\title{
Price Volatility in the Natural Gas Market
}

\author{
Duong Le \\ Business and Economics Deparment, Marietta College \\ Marietta, Ohio, USA \\ Tel: 1-740-376-4769_E-mail:dt1001@marietta.edu
}

Received: August 28, $2017 \quad$ Accepted: Sept. 4, $2017 \quad$ Published: Sept. 7, 2017

doi:10.5296/ifb.v4i2.11768 URL: http://dx.doi.org/10.5296/ifb.v4i2.11768

\begin{abstract}
This paper examines the causes and behavior of price volatility in the US natural gas market. Although natural gas prices are among the most volatile, they have received limited academic scrutiny heretofore. The study's main findings are: (1) the natural gas market is characterized by volatility persistence, (2) predicted volatility increases more following a positive shock than an equal negative shock, (3) there are day-of-the-week and month-of-the-year patterns in this market, (4) surprises in the change in natural gas in storage cause increased volatility, (5) volatility tends to be higher during and immediately after bid week, and (6) volatility tends to be higher on winter days when the temperature is lower than normal. The model developed and employed in this research is an improved procedure for testing and quantifying the hypothesized volatility determinants within a GARCH type model.
\end{abstract}

Keywords: energy, volatility, GARCH 


\section{Introduction}

This paper examines the causes and behavior of price volatility in the US natural gas market from January 1997 through December 2012. Natural gas is one of the most essential energy sources in the U.S., accounting for about $25 \%$ of the nation's energy consumption. Trading activity in the natural gas market has increased significantly in recent years. In October 2006 the New York Mercantile Exchange (NYMEX) reported that the daily trading of natural gas futures reached 54,213 contracts. By January 2013, the number increased more than tenfold to 564,791 and subsequently increased to a record high of 736,238 contracts in January 2014 (Note 1).

The natural gas market has undergone revolutionary changes since the early 1990s. From a highly regulated market in which government regulations prescribed everything from prices to who could buy, sell, and transport natural gas and under what conditions, the natural gas market has evolved into a largely deregulated market in which prices are driven by supply and demand. Since then, natural gas has been one of the most volatile markets. For example, from less than $\$ 2.5$ per million British thermal units (mmBtu) in July 2002, natural gas prices increased to $\$ 9.5$ per mmBtu in February 2003. In 2008, natural gas prices rose sharply from $\$ 7.8$ per mmBtu in early January to $\$ 13.5$ per mmBtu in July, which was the highest price level for that time of year. Then starting around the end of July, natural gas prices fell almost as sharply and were approximately $\$ 5.5$ per mmBtu toward the end of 2008 . According to the U.S. Energy Information Administration (EIA), this decline in natural gas price resulted from a combination of a larger-than-expected increase in domestic gas production and a drop in oil prices. This large price fluctuation tendency has continued in recent years. In 2014, from $\$ 3.95$ per mmBtu in January, natural gas prices increased to $\$ 6.20$ in February before decreasing to $\$ 4.18$ in March.

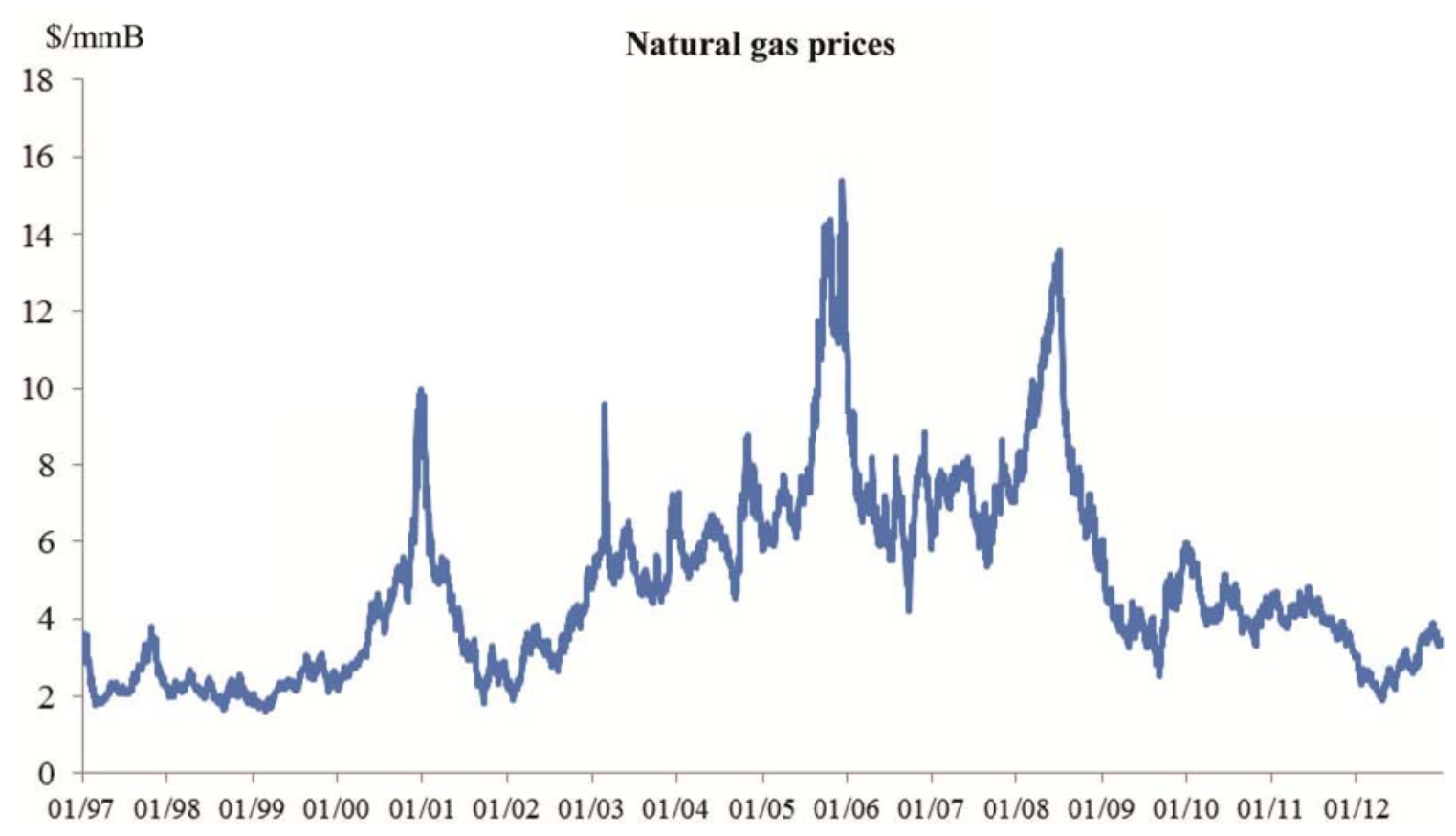




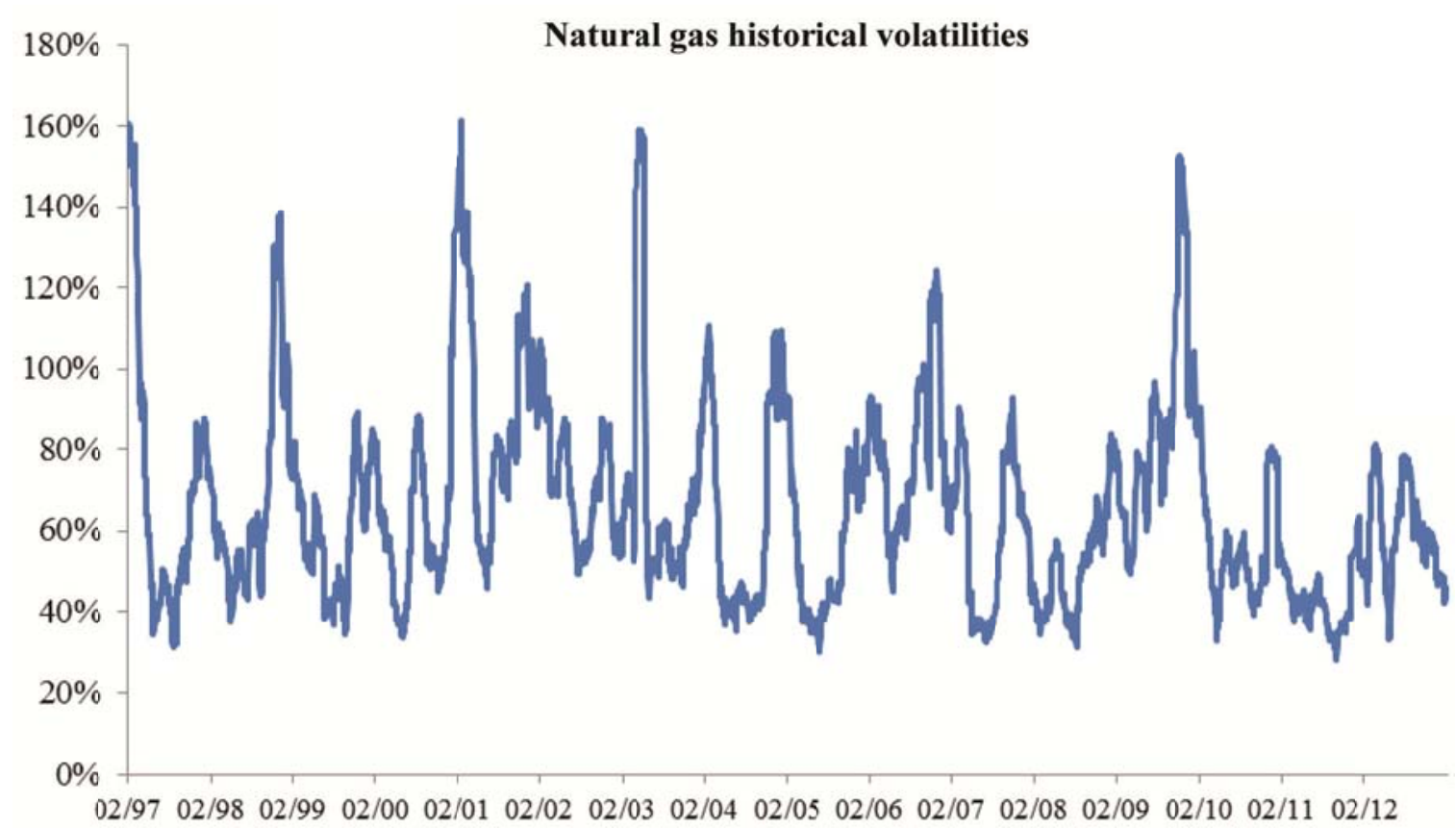

Figure 1. Natural gas prices and historical volatilities from January 1997 through December 2012

This figure presents natural gas prices and historical volatilities from January 1997 through December 2012. The vertical axes depict nearby futures prices and annuallized rolling 30-day standard deviations of returns.

Natural gas prices are more volatile than those in most financial markets. In 2012, the annualized standard deviation of the daily percentage price change was $49.94 \%$ for natural gas. By comparison, that number was only $4.08 \%$ for the US dollar-Euro exchange rate, $16.37 \%$ for the S\&P $500,19.10 \%$ for the 10 -year T-bond interest rates, and $31.33 \%$ for crude oil (Note 2). Figure 1 depicts prices and historical volatilities of the nearby natural gas futures contract from January 1997 through December 2012 wherein historical volatilities are measured as the annualized rolling 30-day standard deviation of returns. As shown in these graphs, the natural gas market has undergone notable price fluctuations during the sample period and there is a time-of-the-year pattern in which volatility tends to increase in winter.

The high volatility in natural gas prices is likely due to the short-term inelasticity of supply and demand. Since natural gas supplies are often constrained by storage levels and imports are limited, natural gas suppliers are unable to increase production levels in a short period of time. Meanwhile, it is difficult for consumers to quickly reduce their consumption when a sharp increase in natural gas prices occurs, especially during the winter. As natural gas suppliers cannot rapidly adjust their production levels to match demand changes, supply and demand imbalances may result in sharp price changes. This high variability in natural gas prices makes it extremely difficult for consumers to forecast their costs and for producers to forecast their profits. The desire to protect market participants against such price fluctuations has led to the creation of and active trading in futures, swaps and options where the market 
value of the latter depends on volatility. An understanding of the causes and behavior of natural gas volatility is therefore essential to measuring and managing the risk faced by market participants.

Although it is difficult to forecast the direction of future price changes from past price behavior, the absolute magnitude of price changes, i.e., volatility, has been proven much more predictable in most financial markets. It is generally found that highly volatile periods tend to be followed by volatile periods whereas stable periods tend to be followed by stable periods. The vast majority of the research on market volatility has focused on the volatility of financial markets such as the stock, bond, interest rates and foreign exchange futures markets, etc. Despite the fact that natural gas prices tend to be more volatile than most financial and commodity prices, research into the causes and behavior of volatility in the natural gas market is limited.

The limited studies on natural gas volatility to date examine several determinants of natural gas volatility in isolation. Susmel \& Thompson (1997), Pindyck (2004) and Murry \& Zhu (2004) find that natural gas volatility follows an ARCH-GARCH type process, Linn and Zhu (2004) document an increase in natural gas volatility following the release of the Weekly Natural Gas Storage Report announcement, Murry \& Zhu (2004) document that natural gas volatility increases on Monday and on days the Storage Report is released, $\mathrm{Mu}$ (2007) examines the impact of storage and weather conditions on natural gas volatility, and Suenaga, Smith, \& Williams (2008) find higher natural gas volatility in the winter.

This study combines these volatility determinants in a single econometric model and also tests and quantifies other hypothesized determinants of natural gas volatility such as asymmetric volatility, bid week effect and month-of-the-year volatility pattern. This study's most important results and contributions to the literature include the following. One, natural gas volatility is asymmetric in that an unexpected increase in price increases predicted volatility more than an unexpected decrease in price of similar magnitude. To my knowledge, this asymmetry pattern is unique to natural gas. Two, natural gas volatility is significantly higher on Monday, implying that the natural gas market is impacted by news occurring during the weekend, and on Thursday, the release day of the Natural Gas Weekly Update. Three, surprises in a change in natural gas in storage tend to cause increased volatility. Four, there is a month-of-the-year pattern in the natural gas market in that volatility tends to increase in the winter months. Five, volatility tends to be high on winter days when the temperature is lower than normal. Six, volatility tends to increase during bid week, the last five trading days of a month, and on days immediately following bid week. Seven, a model which fails to control for seasonality, announcement, weather and bid week effects tends to overestimate the impact of a return shock on subsequent volatility.

This research develops and uses a variant of the regime-switching GARCH type model outlined in Jones, Lamont, \& Lumsdaine (1998). This model, which separates volatility into a persistent part and a transitory part, allows us to implement a much cleaner study of volatility determinants than that used in several previous studies. To the best of my knowledge, this study is the first comprehensive study of the determinants of volatility within a GARCH 
framework for the natural gas market.

The paper is organized as follows. Section 2 reviews the most relevant literature and develops additional hypotheses. The data is presented in Section 3. The multiplicative GARCH type model to quantify the determinants of natural gas volatility is analyzed in Section 4 and the results are presented in Section 5. Section 6 presents results from the robustness check. Section 7 concludes the paper.

\section{Literature Review and Hypotheses}

Several of the natural gas volatility determinants studied in this paper have been examined before individually. Susmel \& Thompson (1997), Murry \& Zhu (2004), and Mu (2007) have estimated ARCH-GARCH type models of natural gas volatility and have consistently found evidence of volatility persistence, i.e., volatile periods tend to follow volatile periods whereas stable periods tend to follow stable periods.

Susmel \& Thompson (1997) find that in the natural gas market, a negative shock has more impact on predicted volatility than a positive shock of the same magnitude while Murry \& Zhu (2004) and $\mathrm{Mu}$ (2007) find no evidence of asymmetric volatility in this market. Contrary to the findings in Susmel \& Thompson (1997), Murry \& Zhu (2004), and Mu (2007), there are good reasons to expect that in the natural gas market, a positive shock could have more impact on predicted future volatility than an equivalent negative shock. The reasoning behind this hypothesis is based on the likely shape of the natural gas supply and demand curves. At low volume and prices, natural gas supply is highly elastic, but once storage limits are reached, supply becomes quite inelastic as natural gas producers, due to infrastructure constraints, are unable to increase their production levels within a short period of time (Krichene, 2002; Burns, 2008). The inelasticity of natural gas supplies is also caused by the fact that the U.S. gas market, although tightly integrated with the Canadian gas market, is relatively isolated from overseas natural gas supplies (Note 3). The natural gas demand curve also contains an elastic portion when prices are low and an inelastic portion when prices are high (Krichene, 2002; Burns, 2008). Given the hypothesized shape of the natural gas supply and demand curves, the same fluctuation in demand when prices are low should cause a smaller change in prices than when prices are high. Thus, a positive price shock which moves the natural gas market up the supply and demand curves is likely to presage higher future volatility than a negative shock moving the market down the curves.

Regarding a day-of-the-week volatility pattern, Murry \& Zhu (2004) find higher volatility on Monday which is attributable to the accumulation of information over the weekend, and on Wednesday, the day the American Gas Association (AGA) released its Weekly Natural Gas Storage Report from November 1997 to August 2003. The Storage Report, which "provides an estimate of the change in inventory levels for working gas in storage facilities across the United States" (Note 4), is widely considered to be one of the most important news release for the natural gas market (Linn \& Zhu, 2004). Linn \& Zhu (2004) find that the release of the Storage Report causes increased volatility in the natural gas market for about 30 minutes following the announcement. This research attempts to simultaneously test for both day-of-the-week and storage announcement effects on volatility. If volatility increases on a 
certain day of the week due to storage announcement, that day-of-the-week pattern should disappear when the model controls for the impact of storage surprise on volatility (Andersen \& Bollerslev, 1998).

Although it is generally argued that natural gas prices are weather-sensitive, (Fleming, Kirby, \& Ostdiek, 2006; Chiou-Wei, Linn, \& Zhu, 2007; Mu, 2007), a time-of-the-year natural gas volatility pattern has received little attention in the literature. (Note 5) This study hypothesizes that natural gas volatility increases in winter even after other determinants are controlled for. This time-of-the-year pattern in natural gas volatility is possibly caused by periodic imbalances between supply and demand during the winter months. The demand for natural gas often displays a substantial fluctuation in winter and occasionally spikes during a cold snap. At the same time, however, the supply of natural gas is essentially fixed in winter due to storage capacity and limited imports (EIA Publication, 2012). Therefore, possible supply and demand imbalances in winter may cause large price swings in the natural gas market. This observation motivates the hypothesis of higher natural gas volatility in the winter months.

Consistent with the argument that natural gas prices are weather-sensitive, Mu (2007) finds that weather surprise (the deviation of temperatures from normal) has a significant effect on the conditional volatility of natural gas prices. This research hypothesizes that the impact of weather on natural gas volatility is still robust after the time-of-the-year volatility pattern is controlled for.

Another seasonality pattern examined in this study is the behavior of volatility during the last five trading days of a month, which is known as "bid week" in the natural gas market. Although the daily spot market is active for natural gas and gas transactions are done in terms of volume per day, the standard market practice is to deal for a month at a time and the majority of gas trading occurs during the bid week. During these five trading days, buyers and sellers arrange for the purchase and sale of physical natural gas to be delivered throughout the coming month and the average prices set during bid week are commonly the prices used in spot contracts over the coming month. (Note 6)

During bid week, as marketers' bids for natural gas to be delivered in the coming month are revealed and spot contracts are signed, this sort of news should contain information relevant to the futures market. This is akin to announcement effect documented in Ederington \& Lee (1993, 1995) for the T-bond, interest rates and foreign exchange markets, in Flannery \& Protopapadakis (2002) for the stock market, and in Linn \& Zhu (2004) for the natural gas market, among others. This study hypothesizes that natural gas volatility increases during bid week. As documented in Ederington \& Lee $(1993,1995)$ and others, volatility tends to increase when lots of new information is coming to the market. In addition to an announcement effect, volatility in the natural gas futures market should increase during bid week also due to the expiration of nearby futures contracts. The first three trading days of bid week is the period when nearby futures contracts are expiring and traders are having to reverse their positions and therefore, could be characterized by high volatility.

Previous studies on scheduled announcement effects (Ederington \& Lee, 1993, 1995; Jones, 
Lamont, \& Lumsdaine, 1998; Flannery \& Protopapadakis, 2002; Linn \& Zhu, 2004, among others) have consistently found evidence that prices tend to complete adjusting to new information within the announcement day since news becomes available to all market participants at the same expected time. Subsequently, volatility tends to fall back to near normal level the following day.

However, "bid week" information is different from scheduled announcements in that while the latter arrives in the market at the same time, information about prices and volumes being set in the spot markets tends to leak out from many spot contract signings and does not fully become public knowledge until the following day. Consequently, natural gas volatility should continue to increase on the day following bid week as all "bid week" news becomes public.

As noted above, previous studies on natural gas volatility consider only one or two possible determinant types. In other words, they test for volatility persistence and/or day-of-the-week, for announcement effect or weather effect but not all four. This study extends the research in natural gas volatility in several dimensions. First, the paper simultaneously estimates GARCH, seasonality, announcement and weather effects as well as testing for a possible volatility asymmetry in one single econometric model. Second, the paper tests and quantifies several unexplored determinants of natural gas volatility such as bid week volatility patterns. Third, as explained further in Section 4, the model used in this study affords a cleaner test of seasonality, announcement and weather effects than that in previous studies.

\section{Data and Preliminary Analysis}

\subsection{Natural Gas Prices}

This study examines natural gas volatility using daily prices of the NYMEX nearby futures contracts from January 02, 1997 to December 31, 2012. The daily trading data is obtained from the U.S. Energy Information Administration (Note 7). Natural gas futures contracts, which began trading on the NYMEX on April 3, 1990, trade in units of 10,000 million British thermal units (mmBTu).

Futures prices are used in place of spot prices for the following reasons. First, the NYMEX natural gas futures price is widely used as a national benchmark price. Natural gas futures prices are also the prices reported in newspapers. Second, the futures market for natural gas is liquid and centralized while spot markets are localized and illiquid. Third, futures prices are the prices normally used in most risk management contracts such as swaps and options.

Two measures of daily natural gas volatility are used in this study. The first volatility measure is based on a GARCH type model. In this framework, daily log returns (Note 8 ) are defined as $r_{t}=\ln \left(P_{t} / P_{t-1}\right)$ wherein $P_{t}$ is the closing price of the nearby futures contract on day $t$ and $P_{t-1}$ is the price of the same contract the previous day. As traders often cover their positions on the last trading day of a contract's life, trading volume and open interest decline and price volatility increases substantially on that day. To avoid this "thin market" problem, return of the nearest contract on the last trading day of each month is replaced with that of the second nearest contract when the $r_{t}$ series are constructed. 
To check the robustness of the GARCH type estimation results, this study utilizes a second volatility measure which is the extreme value estimator developed by Parkinson (1980) and used in numerous studies including Wiggins (1992), Martens \& Van Dijk (2007) and Cao, Chang, \& Wang (2008), among others. In the extreme value method, intraday volatility on day $t$ is calculated as:

$$
\text { Variance }_{t}=\frac{\left(\ln \left(\text { High }_{t}\right)-\ln \left(\text { Low }_{t}\right)\right)^{2}}{4 \ln (2)}
$$

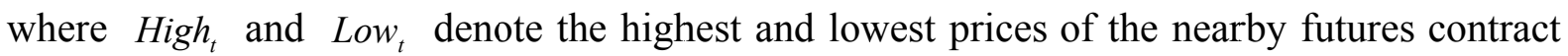
on day $t$, respectively. As Parkinson (1980) shows, this measure can be used as an estimator of the variance of the price if the latter follows a random walk with zero drift. (Note 9)

Table 1. Summary statistics

\begin{tabular}{|l|l|l|l|}
\hline & Returns & Absolute Returns & Extreme value estimator \\
\hline Mean $\left(\mathrm{x} 10^{2}\right)$ & 0.0340 & 2.7597 & 2.8610 \\
\hline Maximum & 0.3244 & 0.3244 & 0.1950 \\
\hline Minimum & -0.1990 & 0.0000 & 0.0012 \\
\hline Std Dev & 0.0382 & 0.0264 & 0.0148 \\
\hline Annualized Std Dev & 0.6219 & 0.4298 & \\
\hline Skewness & 0.4570 & 2.6122 & 2.7047 \\
\hline Kurtosis & 8.0764 & 16.6902 & 21.9202 \\
\hline Rho (First order autocorrelation coefficient) & -0.0614 & $0.1151^{* *}$ & $0.3941^{* *}$ \\
\hline
\end{tabular}

This table presents summary statistics for natural gas returns, absolute returns and extreme value estimators of volatility. The second column presents summary statistics for daily returns, $r_{t}$, where $r_{t}=\ln \left(P_{t} / P_{t-1}\right) ; P_{t}$ is the price of the nearby futures contract on day $t$ and $P_{t-1}$ is the price of the same futures contract on the previous day. The third column presents summary statistics for absolute values of daily returns. The fourth column presents summary statistics for extreme value estimators of volatility, $S t d_{t}$, where $S t d_{t}=\frac{\left|\ln \left(H i g h_{t}\right)-\ln \left(L o w_{t}\right)\right|}{2 \sqrt{\ln (2)}}, H i g h_{t}$ and Low $w_{t}$ denote the highest and the lowest prices of the nearby natural gas futures contract on day $t$, respectively. $\left({ }^{* *}\right)$ on Rho designates estimates significantly different from zero at the 0.01 level. The sample extends from January 02, 1997 to December 31, 2012.

Table 1 provides summary statistics of daily returns and extreme value volatility estimate of natural gas nearby futures prices. The annualized standard deviation of the daily percentage change in nearby natural gas prices over the January 1997-December 2012 period is $62.19 \%$, 
indicating a highly volatile natural gas market. Table 1 shows preliminary evidence of volatility persistence in that the first-order autocorrelation coefficients for absolute returns and for extreme value estimator of volatility are positive and significant at the 0.01 level. For squared returns (not reported), the first-order autocorrelation coefficient is also significantly positive at the 0.001 level. Clearly, the natural gas market, like many others, is characterized by volatility persistence.

\subsection{Natural Gas Storage Data}

The actual storage announcement data are collected from various issues of the Weekly Natural Gas Storage Report issued by the U.S. Energy Information Administration (EIA). The Storage Report was compiled and released by the American Gas Association (AGA) prior to April 10, 2002 and by the EIA since then. The report contains the actual level of natural gas in storage and change in the level of storage in three regions, Consuming East, Consuming West, and Producing Region, as of each Friday. The Report was released on Wednesday (prior to May 06, 2002) and on Thursday (after May 06, 2002) of the subsequent week.

Several years after the first Storage Report was released in 1994, analysts from the consulting industry, production companies and investment banks began providing their weekly forecasts of storage changes and the implied storage levels to be released in the Storage Report. To facilitate the public dissemination of these analyst forecasts, Bloomberg, a major market information vendor, solicits forecasts from analysts, computes a consensus estimate and publishes this information electronically in advance of the Storage Report release (Note 10). The Bloomberg survey of predicted changes in storage is generally regarded as the best available amongst practitioners. The survey also represents the forecasts that are most readily available to market participants (Chiou-Wei, Linn, \& Zhu, 2007; and Gay, Simkins, \& Turac, 2007). Following Chiou-Wei et al. (2007) and Gay et al. (2007), this study assumes that natural gas market participants condition their expectation of the weekly storage change to equal the Bloomberg consensus analyst forecast. Consequently, this paper uses survey data available on Thursday morning prior to the release of the EIA report as a proxy for the market's expectation of natural gas storage change before the announcement.

\subsection{Weather Data}

Weather data are obtained from the National Climatic Data Center (NCDC), a division of the National Oceanographic and Atmospheric Administration (NOAA), Department of Commerce. Following the industry convention, this research controls for weather conditions using two measures. A Cooling Degree Day (CDD) is one for which the actual temperature minus 65 degrees $\mathrm{F}$ is greater than zero. The first calendar day dummy is assigned the value of the difference when this is the case and 0 otherwise. A Heating Degree Day (HDD) occurs when 65 degrees $\mathrm{F}$ minus the actual temperature is greater than zero. The second calendar day dummy is assigned the degree difference when this condition is met and 0 otherwise. Therefore, each day receives both a CDD measure and an HDD measure. The dataset contains variables measuring daily actual temperature and the data on normal condition defined as the previous 30 years' average temperature as of the relevant date. Weather data are obtained from weather reporting stations in the following main consumption regions: 
Chicago, New York, Atlanta, and Dallas.

\section{Model Specification and Analysis}

In order to test and quantify the determinants of natural gas volatility as discussed in section 2, this study estimates a model in which the conditional variance follows a regime-switching GARCH type process:

$r_{t}=\mu+a_{1}$ Oilret $_{t}+a_{2}$ CddDif $_{t}+a_{3}$ HddDif $_{t}^{\{+\}}+a_{4}$ HddDif $_{t}^{\{-\}}+a_{5}$ SRFE $_{t}+\sum_{i=1}^{4} g_{i} D W_{i, t}+\varepsilon_{t}$

where

$$
\begin{gathered}
\varepsilon_{t} \sim \mathrm{N}\left(0, \sigma_{t}^{2},\right) \text { and } \sigma_{t}^{2}=h_{t} \cdot s_{t} \\
h_{t}=\operatorname{Var}\left(\zeta_{t}\right)=\omega+\alpha \zeta_{t-1}^{2}+\beta h_{t-1}+\gamma \zeta_{t-1}^{2} I_{t-1}, \\
s_{t}=\prod_{i=1}^{5} s_{i, t} \\
s_{1, t}=\prod_{i=1}^{4}\left(1+\lambda_{i} D W_{i, t}\right) \\
s_{2, t}=\left(S R_{t}\right)^{\kappa} \\
s_{3, t}=\prod_{i=1}^{11}\left(1+\theta_{i} D M_{i, t}\right) \\
s_{4, t}=\left(1+\psi W_{t}\right) \\
s_{5, t}=\left(1+\delta_{0} B W_{t}\right)\left(1+\delta_{1} A B W_{t}\right)
\end{gathered}
$$

The purpose of equation 1 (the mean equation) is to remove predictable changes in natural gas returns thereby obtaining the surprise return $\varepsilon_{t}$ whose volatility is examined in the study. The specification of the mean equation is motivated by Chiou-Wei et al. (2007) and Mu (2007) who find that (1) changes in natural gas prices are statistically significantly and positively related to changes in crude oil prices, (2) weather shock, which is a proxy for natural gas demand, tends to have some impact on natural gas prices, and (3) natural gas prices strongly react to the "surprise" component in the natural gas Storage Report.

In equation (1), $r_{t}$ is the log percentage change in price of the nearby natural gas futures contract on day $t$; Oilret $_{t}$ is the log percentage change in price of the nearby crude oil futures contract on day $t$; CddDif $f_{t}$ is the difference between the actual Cooling Degree Day measure and the 30-year average CDD measure for day $t$; HddDif $f_{t}$ is the difference between the actual Heating Degree Day measure and the 30-year normal HDD measure for day $t, \operatorname{HddDif}_{t}{ }^{\{+}=$ $H_{d d D i f}$ if HddDif $_{t}>0$ and 0 otherwise, HddDif $f^{\{-\}}=H_{d d D i f}$ if HddDif $<0$ and 0 otherwise; 
$S R F E_{t}$ is the surprise in the change in storage which is defined as the actual storage change as reported in the EIA storage survey minus the consensus expected storage change as reported by Bloomberg prior to the EIA report release; $D W_{i, t}$ are zero-one dummies for Monday (which includes the weekend), Wednesday, Thursday and Friday with Tuesday being the left-out day.

The mean equation is not the focus of this paper. The main interest is in the determinants of the variance of the surprise natural gas return, $\varepsilon_{t}$. This variance is modeled as a multiplicative function of an asymmetric GARCH function (equation 3), day-of-the-week pattern (equation 4.a), storage announcement effect (equation 4.b), month-of-the-year pattern (equation 4.c), temperature impact (equation 4.d), and bid week effect (equation 4.e).

\subsection{Volatility Persistence and Asymmetric Volatility}

Equation 3 is the asymmetric GARCH model due to Glosten et al. (1993) often referred to as the GJR or TGARCH model in which $I_{t-1}=1$ if $\zeta_{t-1}<0$ and 0 otherwise. If volatility persistence is an attribute of the natural gas market, $\alpha$ and $\beta$ should be significantly positive, implying that predicted volatility depends on both unexpected price changes and the previous day's forecast volatility. Asymmetric volatility implies $\gamma \neq 0$ in equation (3); $\gamma<0$ implies that a positive shock increases conditional volatility more than an equivalent negative shock.

\subsection{Seasonality Patterns, Storage Announcement, Weather, and Bid Week Effects}

Equation 4, the transitory effects equation, estimates the impact of other hypothesized determinants on volatility.

Equation 4(a) estimates a day-of-the-week pattern in natural gas volatility. $D W_{i, t}$ are zero-one dummies for Monday (which includes the weekend), Wednesday, Thursday and Friday with Tuesday being the left-out day. $\lambda_{i}$ estimates the average percentage difference between volatility on day $i$ and volatility on Tuesday. In other words, assuming that $s_{2, t}=s_{3, t}=s_{4, t}=s_{5, t}=$ 1 , the estimated variance on Tuesday is $h_{t}$. On Monday, the estimated variance is $h_{t}\left(1+\lambda_{M}\right)$. On Wednesday, the estimated variance is $h_{t}\left(1+\lambda_{W}\right)$ and so on for other days. If the natural gas market is impacted by news occurring over the weekend, Monday return (which is a three-day return including the weekend) should be more volatile than any normal weekday return and $\lambda_{M}>0$. Also, if the Natural Gas Storage Report contains price moving information, volatility should be higher on days the report is released. The model does not include a separate dummy variable for storage report announcement days in equation 4 because, since this announcement is released weekly, announcement impact cannot be separated from other possible weekly factors. When the model is used to test for a day-of-the-week volatility pattern, it is anticipated that this weekly announcement will be part of the reason for such a pattern.

Equation 4(b) tests the hypothesis that natural gas volatility is sensitive to the surprise in the change in natural gas in storage. The level of natural gas in storage and the change in natural gas in storage often receive a great deal of attention because they are widely considered significant measures of supply and demand balance in the market (EIA Publication, 2007; $\mathrm{Mu}$, 2007). For example, a low inventory of working gas than the market's expectation may create 
a perception of supply tightness, which places upward pressure on prices. Chiou-Wei, Linn, \& Zhu (2007) find an inverse relation between the change in storage surprise (actual change minus expected change) and futures price change on the days of the EIA storage announcement.

Following Balduzzi, Elton, \& Green (2001), and Andersen, Bollerslev, Diebold, \& Vega (2003), this study defines the standardized change in storage surprise as: $S S R F E_{t}=\frac{\left|S R F E_{t}\right|}{s_{S R}}$ where $S R F E_{t}$ is the surprise in the change in storage = the actual storage change (reported in the EIA report) - the consensus expected storage change (reported by Bloomberg prior to the EIA report release) and $s_{S R}$ is the sample standard deviation of $\left|S R F E_{t}\right|$. Separate variables

for positive surprise and negative surprise are not included in the specification because Chiou-Wei et al. (2007) find no evidence that natural gas prices respond differently to positive surprises as compared to negative surprises. The variable $S R_{t}$ is then defined as: $S R_{t}=$ $S S R F E_{t}$ on days the storage report announcement is released and $S R_{t}=1$ on other days since Chiou-Wei et al. (2007) find that the market's assessment of the level of natural gas in storage (as measured by the difference between the consensus Bloomberg forecast and the 5-year average volume) is unrelated to the price change on non-announcement days. If larger storage surprises are associated with larger futures price changes, $\kappa$ should be $>0$.

In equation 4(c), $D M_{i, t}=1$ if the futures contract observed on day $t$ expires in month $i . \theta_{i} \neq 0$ imply a month-of-the-year volatility pattern. In equation $4(\mathrm{~d}), W_{t}=1$ if the difference between the actual Heating Degree Day measure and the 30-year normal HDD measure for day $\mathrm{t}$ (HddDif $f_{t}$ ) is $<0$ and $\mathrm{W}_{\mathrm{t}}=0$ otherwise. The model does not include dummy variables for days when $C d d D i f_{t} \neq 0$ or when $H d d D i f_{t}>0$ since results from the mean equation do not indicate that $C d d D i f_{t}$ and $H d d D i f_{t}{ }^{\{+\}}$have significant impact on natural gas prices.

Equation 4(e) estimates the behavior of natural gas volatility around bid week. $B W_{t}$ is 1 if day $t$ is one of the last five trading days in a month and 0 otherwise. It is hypothesized above that $\delta_{0}>0 . A B W_{t}$ is used as dummy for the day after bid week. If prices and volumes set during bid week leak from contract signings rather than being available to all market participants at the same time as in the case for scheduled announcements, part of bid week information is not public knowledge until right after bid week. Therefore, volatility should increase when all information becomes public and $\delta_{1}>0$.

\subsection{Comparison with Previous Models}

Specification (1-4) improves on models used in several previous studies for natural gas and other markets which seek to simultaneously estimate both GARCH and other determinants of volatility. The introduction of a transitory volatility equation $s_{t}$ into the specification enables us to implement a much cleaner study of the determinants of volatility than when announcement and/or day-of-the-week dummies are added to the variance equation. For instance, Hsieh (1989), Berument \& Kiymaz (2001), Ederington \& Lee (2001) and Lee (2002) use GARCH type models to examine day-of-the-week effects on volatility in the foreign 
exchange, stock, and interest rates markets and Murry \& Zhu (2004) in the natural gas market. In those studies, weekday dummies are in the $h_{t}$ equation (equation 3 ) and the coefficient estimates reflect how conditional volatility changes across weekdays. Thus, using their model, there is no $s_{t}$ equation (equation 4) and equation (3) becomes:

$$
h_{t}=\omega+\alpha \varepsilon_{t-1}^{2}+\beta h_{t-1}+\lambda_{M} D W_{M, t}+\lambda_{W} D W_{W, t}+\lambda_{R} D W_{R, t}+\lambda_{F} D W_{F, t}
$$

In equation 5 , since weekday dummies are in the $h_{t}$ equation, the dummy for any day of the week impacts volatilities on all days of the week through the $h_{t-1}$ term on the right hand side of the equation. Suppose, for instance, that day $t$ is Monday. $\partial h_{t} / \partial D W_{M, t}=\lambda_{M}$. Now consider the impact of the Monday dummy on volatility on Tuesday (day $t+1$ ). Since

$$
h_{t+1}=\omega+\alpha \varepsilon_{t}^{2}+\beta h_{t}+\lambda_{M} D W_{M, t+1}+\lambda_{W} D W_{W, t+1}+\lambda_{R} D W_{R, t+1}+\lambda_{F} D W_{F, t+1},
$$

$\partial h_{t+1} / \partial D W_{M, t}=\left(\partial h_{t+1} / \partial h_{t}\right)\left(\partial h_{t} / \partial D W_{M, t}\right)=\beta \lambda_{M}$. Likewise, the Monday durmmy impact on the Wednesday's volatility is $\partial h_{t+2} / \partial D W_{M, t}=\beta^{2} \lambda_{M}$. Therefore, when weekday dummies are in the $h_{t}$ equation, as in equation (5), $\lambda_{M}$ does not measure how much higher volatility is on Monday than on the omitted day (Tuesday). Indeed, depending on the coefficient pattern, day $X$ which has the highest $\lambda_{X}$ coefficient may not be the day with the highest volatility.

In contrast, a specification which separates the variance of returns into a persistent part, equation (3), and a non-persistent part, equation (4), allows us to estimate a model in which any weekday dummy impacts that day's volatility only. For example, $\lambda_{M}$ measures how much higher (or lower) in percentage terms the volatility is on Monday than on the omitted day (Tuesday) and $\lambda_{W}$ measures how much higher (or lower) the volatility is on Wednesday and so on.

To estimate the announcement impacts on volatility, several previous studies, for example, Hsieh (1989), Berument \& Kiymaz (2001), Ederington \& Lee (2001), De Goeij \& Marquering (2006) for other markets and $\mathrm{Mu}$ (2007) for the natural gas market, add an announcement dummy to the $h_{t}$ equation and do not include the $s_{t}$ equation. Thus, the variance equation becomes:

$$
h_{t}=\omega+\alpha \varepsilon_{t-1}^{2}+\beta h_{t-1}+\delta_{0} D A_{t},
$$

In equation (6), an unscheduled shock on day $t-1$ impacts volatility on day $t$ through the term $\alpha \varepsilon_{t-1}{ }^{2}$. However, since an announcement impact is forced to persist on the subsequent days $\left(\partial h_{t} / \partial D A_{t}=\delta_{0}, \partial h_{t+1} / \partial D A_{t}=\left(\partial h_{t+1} / \partial h_{t}\right)\left(\partial h_{t} / \partial D A_{t}\right)=\beta \delta_{0}, \partial h_{t+2} / \partial D A_{t}=\beta^{2} \delta_{0}\right.$ and so on $)$, the impact of a shock due to day $t$-l's scheduled announcement on day $t$ 's volatility includes not only $\alpha \varepsilon_{t-1}^{2}$ but also $\beta \delta_{0}$. Consequently, models like equation (6) impose much higher persistence for shocks due to scheduled announcements than for equivalent shocks due to unscheduled announcements. In contrast, in specification (1-4), the impact of a shock due to storage announcement does not persist on the following days $\ln \left(\partial \sigma_{t}^{2} / \partial S R_{t}\right)=\kappa$ and $\ln \left(\partial \sigma_{t+1}^{2}\right) / \partial S R_{t}=0$ and therefore, the estimated impact of day $t-1$ 's shock on the following day t's volatility is the same for scheduled and unscheduled announcements. 


\section{Macrothink}

\section{Results}

Since the data of analysts' forecast of natural gas storage is available in Bloomberg starting May 03, 2002, this study estimates specification (1-4) without storage surprise variables in the mean and variance equations for the sample period January 1997-December 2012 and estimate the full specification (1-4) for the sub-period May 2002-December 2012. The last three columns of Panel A and Panel B in Table 2 present the results for the 1997-2012, 1997-2002 and 2002-2012 periods, respectively.

Table 2. The multiplicative GARCH-type model of volatility determinants

Panel A. Mean equation

\begin{tabular}{|l|l|l|l|}
\hline & $1997-2012$ & $1997-2002$ & $2002-2012$ \\
\hline$\mu$ & 0.1580 & -0.003 & 0.2398 \\
\hline & $(0.1565)$ & $(0.2324)$ & $(0.1648)$ \\
\hline Oilret & $0.4632^{* * *}$ & $0.3320^{* * *}$ & $0.5329^{* * *}$ \\
\hline & $(0.0304)$ & $(0.0416)$ & $(0.0502)$ \\
\hline CddDif & 0.0443 & 0.0145 & 0.0870 \\
\hline & $(0.0435)$ & $(0.0307)$ & $(0.0715)$ \\
\hline HddDif ${ }^{\prime+\}}$ & 0.0016 & -0.0023 & 0.0060 \\
\hline & $(0.0221)$ & $(0.0309)$ & $(0.0304)$ \\
\hline HddDif ${ }^{\prime-j}$ & $-0.0362^{*}$ & 0.0216 & $-0.0559^{*}$ \\
\hline & $(0.0188)$ & $(0.0269)$ & $(0.0230)$ \\
\hline Monday & -0.1523 & 0.06262 & -0.3291 \\
\hline & $(0.2269)$ & $(0.3369)$ & $(0.2803)$ \\
\hline Wednesday & -0.2572 & -0.4183 & -0.0500 \\
\hline & $(0.2214)$ & $(0.3284)$ & $(0.2261)$ \\
\hline Thursday & -0.2759 & 0.17503 & $-0.6216^{* *}$ \\
\hline & $(0.2225)$ & $(0.3299)$ & $(0.2453)$ \\
\hline Friday & -0.0356 & 0.34631 & $-0.4796^{* *}$ \\
\hline & $(0.2248)$ & $(0.3336)$ & $(0.2037)$ \\
\hline SRFE & & & $-0.0636^{* * *}$ \\
\hline & & & $(0.0148)$ \\
\hline
\end{tabular}

Panel B. Variance Equation

\begin{tabular}{|l|l|l|l|l|}
\hline & GJR model & Full model & \multicolumn{2}{l|}{} \\
\hline & & $1997-2012$ & $1997-2002$ & $2002-2012$ \\
\hline$\omega$ & $0.3673^{* * *}$ & $0.1668^{* * *}$ & $0.1677^{*}$ & $0.1677^{* *}$ \\
\hline & $(0.0652)$ & $(0.0483)$ & $(0.0742)$ & $(0.0660)$ \\
\hline$\alpha$ & $0.0995^{* * *}$ & $0.0691^{* * *}$ & $0.0681^{* * *}$ & $0.0714^{* * *}$ \\
\hline$\beta$ & $(0.0077)$ & $(0.009)$ & $(0.0159)$ & $(0.0137)$ \\
\hline & $0.8869^{* * *}$ & $0.9235^{* * *}$ & $0.9244^{* * *}$ & $0.9007^{* * *}$ \\
\hline$\gamma$ & $(0.0104)$ & $(0.0119)$ & $(0.0193)$ & $(0.0235)$ \\
\hline Monday & $-0.0158^{* *}$ & $-0.0359^{* *}$ & -0.0239 & $-0.0396^{* *}$ \\
\hline & $(0.0088)$ & $(0.0125)$ & $(0.0214)$ & $(0.0174)$ \\
\hline Wednesday & & $0.8772^{* * *}$ & $0.7047^{* * *}$ & $0.8201^{* * *}$ \\
\hline & & $(0.1434)$ & $(0.1914)$ & $(0.1839)$ \\
\hline Thursday & & 0.1080 & 0.1678 & -0.0422 \\
\hline & & $(0.0843)$ & $(0.1288)$ & $(0.0967)$ \\
\hline
\end{tabular}




\begin{tabular}{|c|c|c|c|c|}
\hline & & $(0.1187)$ & $(0.1462)$ & $(0.2016)$ \\
\hline \multirow[t]{2}{*}{ Friday } & & $-0.2575^{* * *}$ & $-0.2640^{* *}$ & $-0.2740^{* * *}$ \\
\hline & & $(0.0576)$ & $(0.0849)$ & $(0.0742)$ \\
\hline \multirow[t]{2}{*}{ January } & & $1.2836^{* *}$ & $1.2888^{*}$ & $1.5620^{* * *}$ \\
\hline & & $(0.3979)$ & $(0.5925)$ & $(0.5736)$ \\
\hline \multirow[t]{2}{*}{ February } & & $1.0768^{* *}$ & $0.8148^{*}$ & $1.5867^{* *}$ \\
\hline & & $(0.3663)$ & $(0.4635)$ & $(0.5825)$ \\
\hline \multirow[t]{2}{*}{ March } & & $0.4082^{*}$ & 0.1985 & $1.7769^{* * *}$ \\
\hline & & $(0.2371)$ & $(0.3270)$ & $(0.6602)$ \\
\hline \multirow[t]{2}{*}{ April } & & -0.1847 & -0.1062 & $0.9597^{*}$ \\
\hline & & $(0.1277)$ & $(0.2351)$ & $(0.4115)$ \\
\hline \multirow[t]{2}{*}{ May } & & -0.3292 & $-0.3109^{*}$ & 0.0804 \\
\hline & & $(0.1031)$ & $(0.1758)$ & $(0.2203)$ \\
\hline \multirow[t]{2}{*}{ July } & & $-0.2519^{* *}$ & -0.1702 & -0.0954 \\
\hline & & $(0.0946)$ & $(0.1779)$ & $(0.1753)$ \\
\hline \multirow[t]{2}{*}{ August } & & 0.0157 & -0.1635 & 0.3141 \\
\hline & & $(0.1455)$ & $(0.1705)$ & $(0.2302)$ \\
\hline \multirow[t]{2}{*}{ September } & & $0.3961^{*}$ & 0.1688 & $0.9475^{*}$ \\
\hline & & $(0.2178)$ & $(0.2564)$ & $(0.4355 i)$ \\
\hline \multirow[t]{2}{*}{ October } & & $1.5795^{* * *}$ & $1.3393^{*}$ & $1.8148^{* *}$ \\
\hline & & $(0.3985)$ & $(0.5977)$ & $(0.6055)$ \\
\hline \multirow[t]{2}{*}{ November } & & $1.2622^{* * * *}$ & $1.2646^{*}$ & $3.4377^{* * * *}$ \\
\hline & & $(0.3626)$ & $(0.5809)$ & $(0.8879)$ \\
\hline \multirow[t]{2}{*}{ December } & & $0.6336^{*}$ & 0.7675 & $2.0524^{* *}$ \\
\hline & & $(0.2926)$ & $(0.5106)$ & $(0.6494)$ \\
\hline \multirow[t]{2}{*}{$W$} & & $0.3158^{* *}$ & 0.1051 & $0.3032^{* * *}$ \\
\hline & & $(0.1093)$ & $(0.1629)$ & $(0.1067)$ \\
\hline \multirow[t]{2}{*}{$B W$} & & $0.6592^{* * *}$ & $0.3065^{* *}$ & $0.8004^{* * * *}$ \\
\hline & & $(0.0925)$ & $(0.1190)$ & $(0.1292)$ \\
\hline \multirow[t]{2}{*}{$A B W$} & & $0.4802^{* *}$ & $0.6451^{*}$ & $0.4595^{*}$ \\
\hline & & $(0.1829)$ & $(0.2789)$ & $(0.2525)$ \\
\hline$S R_{t}$ & & & & $0.2167^{* * 4}$ \\
\hline Log-Likelihood & -7116.32 & -6947.23 & -3560.01 & $\begin{array}{l}(0.0774) \\
-4277.480\end{array}$ \\
\hline
\end{tabular}

Table 2 presents the estimates of the following model:

$$
\begin{aligned}
& r_{t}=\mu+a_{1} \text { Oilret }_{t}+a_{2} \text { CddDif }_{t}+a_{3} \text { HddDif }_{t}^{\{+\}}+a_{4} \text { HddDif }_{t}^{\{-\}}+a_{5} \operatorname{SRFE}_{t}+\sum_{i=1}^{4} \vartheta_{i} D W_{i, t}+\varepsilon_{t} \\
& \varepsilon_{t} \sim \mathrm{N}\left(0, \sigma_{t}^{2}\right) \text { and } \sigma_{t}^{2}=h_{t} \cdot s_{t} \\
& h_{t}=\operatorname{Var}\left(\zeta_{t}\right)=\omega+\alpha \zeta_{t-1}^{2}+\beta h_{t-1}+\gamma \zeta_{t-1}^{2} I_{t-1}, \text { where } \zeta_{t}=\varepsilon_{t} / \mathrm{s}_{t}^{5} \\
& s_{t}=\prod_{\mathrm{i}=1}^{5} s_{i, t} \\
& s_{1, t}=\prod_{i=1}^{4}\left(1+\lambda_{i} D W_{i, t}\right)
\end{aligned}
$$




$$
\begin{gathered}
s_{2, t}=\left(S R_{t}\right)^{\kappa} \\
s_{3, t}=\prod_{i=1}^{11}\left(1+\theta_{i} D M_{i, t}\right) \\
s_{4, t}=\left(1+\psi W_{t}\right) \\
s_{5, t}=\left(1+\delta_{0} B W_{t}\right)\left(1+\delta_{1} A B W_{t}\right)
\end{gathered}
$$

$r_{t}$ is the log percentage change in price of the nearby natural gas futures contract on day $t, \varepsilon_{t}$ is a normally distributed random variable with conditional mean zero and conditional variance $\sigma_{t}^{2}$. Oilret $_{t}$ is the log percentage change in price of the nearby crude oil futures contract on day $t$. CddDif $f_{t}$ is the difference between the actual Cooling Degree Day measure and the 30 -year average CDD measure for day $t ; H_{d d D i f}$ is the difference between the actual Heating Degree Day measure and the 30-year normal HDD measure for day $t, \operatorname{HddDif}_{t}{ }^{\{+}=\mathrm{HddDif}_{t}$ if $H_{d d D i f}>0$ and 0 otherwise, HddDif ${ }_{t}^{\{-\}}=H_{d d D i f}$ if HddDif $f_{t}<0$ and 0 otherwise; SRFE $E_{t}$ is the surprise in the change in storage $=$ the actual storage change as reported in the EIA storage survey - the consensus expected storage change as reported by Bloomberg prior to the EIA report release; $D W_{i, t}$ are zero-one dummies for Monday (which includes the weekend), Wednesday, Thursday and Friday with Tuesday being the left-out day. $I_{t-l}=1$ if $\varepsilon_{t-1}<0$ and 0 otherwise. $S R_{t}=\frac{\left|S R F E_{t}\right|}{S_{S R}}$ on days the storage report announcement is released and 1 otherwise where $s_{S R}$ is the sample standard deviation of $\left|S R F E_{t}\right| . D M_{i, t}=1$ if the futures contract observed on day $t$ expires in month $i . W_{t}=1$ if the difference between the actual Heating Degree Day measure and the 30-year normal HDD measure for day $\mathrm{t}\left(\operatorname{HddDif}_{t}\right)$ is $<0$ and $\mathrm{W}_{\mathrm{t}}=0$ otherwise. $B W_{t}$ is 1 if day $t$ is one of the last five trading days in a month and 0 otherwise. $A B W_{t}$ is 1 if day $t$ is the first trading day in a month and 0 otherwise. Standard errors are shown in parentheses. $\left(^{* * *}\right),\left({ }^{* *}\right),\left(^{*}\right)$ designate estimates significantly different from zero at the $0.001,0.01$ and 0.05 levels, respectively. The sample extends from January 02, 1997 to December 31, 2012.

\subsection{The Mean Equation}

Consistent with the findings in Chiou-Wei et al. (2007) and in Mu (2007), natural gas returns are statistically significantly and positively related to crude oil returns. There is no significant evidence that a departure from normal weather conditions in the summer (CddDif) or on winter days when the temperature is higher than normal $\left(H d d D i f^{(+)}\right)$has significant impact on natural gas prices. However, a departure from the norm on winter days when the temperature is lower than normal $\left(\mathrm{HddDif}^{(-\}}\right)$tends to have a negative impact on naturall gas prices. For the period 05/2002-12/2012, the estimated coefficient for $S R F E_{t}$ is negative and significantly different from zero at the 0.001 level, implying a tendency for natural gas prices to increase 


\section{Macrothink}

on days the EIA releases news of a lower than expected gas in storage and to decrease on news of a higher than expected gas in storage. This result is consistent with the findings in Chiou-Wei et al. (2007) and in $\mathrm{Mu}$ (2007). There is no significant evidence of a day-of-the-week effect in natural gas prices for the sample period 1997-2012 but for the sub-period 05/2002-12/2012, natural gas prices tend to decline on Thursday and Friday.

\subsection{Volatility Persistence and Asymmetric Volatility}

As expected, there is evidence of volatility persistence in the natural gas market. The estimates of $\alpha$ and $\beta$ are positive and significant at the 0.001 level, implying that predicted volatility depends on both previous shocks and previous volatilities. Hence, in the natural gas market, highly volatile periods tend to be followed by volatile periods in the following days. This result is consistent with the findings in Murry \& Zhu (2004) and Mu (2007). However, while Murry \& Zhu (2004) and Mu (2007) find no evidence of asymmetric volatility in the natural gas market, the estimated $\gamma$ in this study is significantly negative, indicating that volatility increases considerably more following a sudden increase in natural gas prices than following an equal sudden decrease in prices. As hypothesized earlier, the behavior of natural gas volatility could mostly be explained by the likely shape of the supply and demand curves. Since the same fluctuation in demand when prices are low should cause a smaller change in prices than when prices are high, a positive price shock which moves the natural gas market up the supply and demand curves is likely to presage higher future volatility than a negative shock moving the market down the curves.

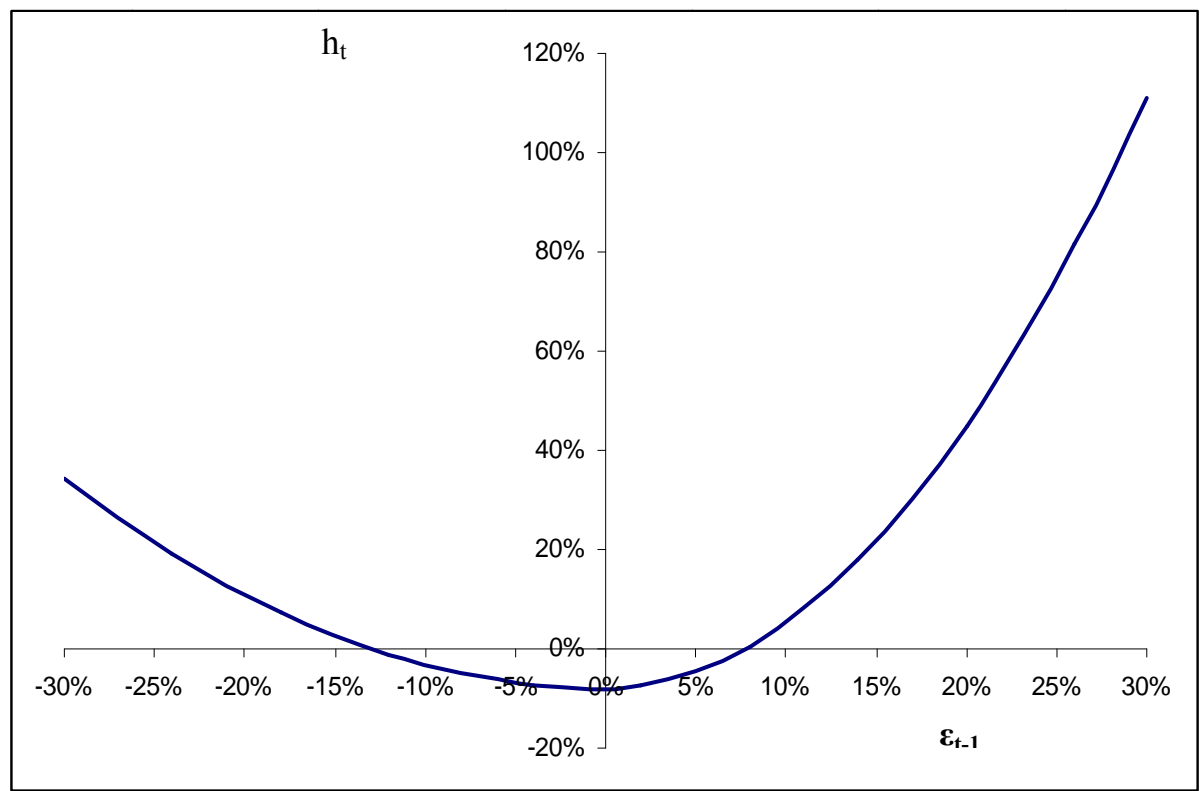


2.b

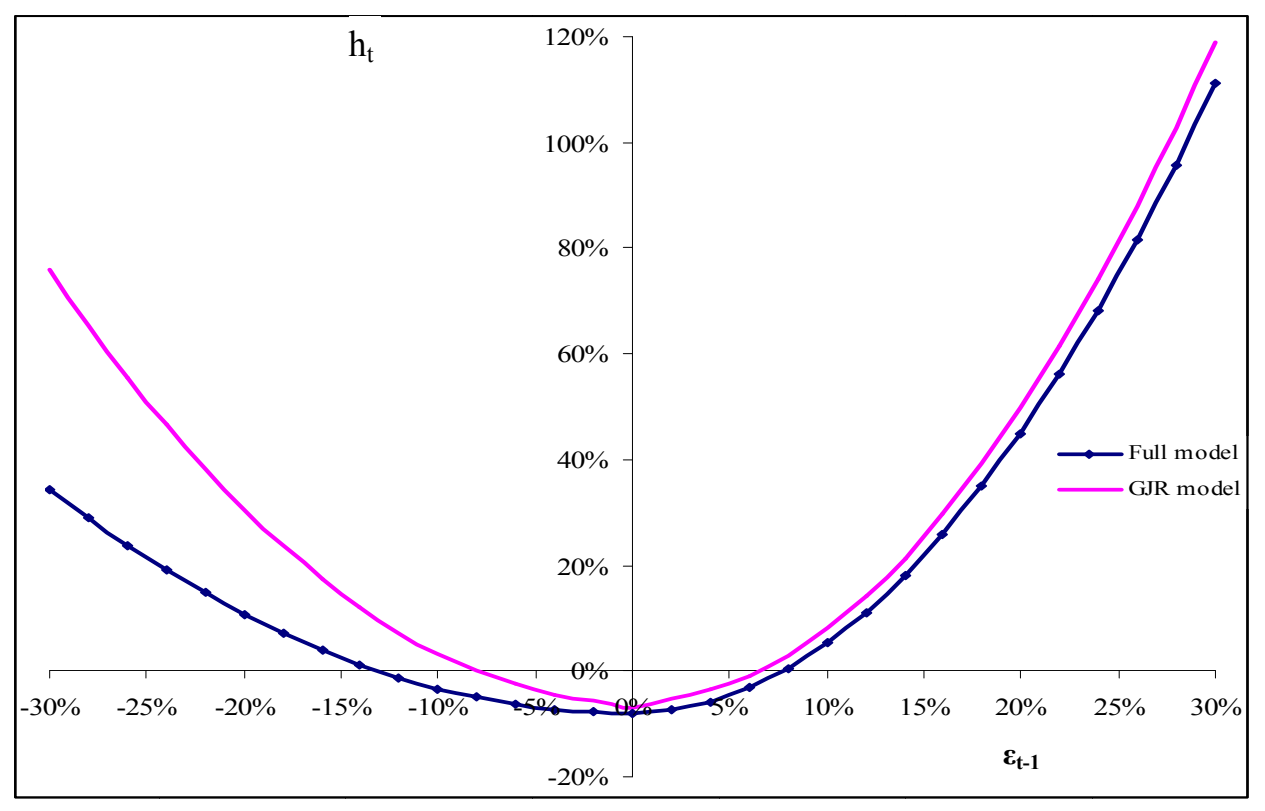

Figure 2. Estimated news impact curves

This figure depicts how equal positive and negative return shocks at time $t-1$ impact predicted volatility in the natural gas market according to the estimates of the GJR model and those of the full model (in the second and third columns of Panel B in Table 2). These curves demonstrate how a return shock in time $t-1, \varepsilon_{\mathrm{t}-1}$, is incorporated into volatility estimates (as measured by $\Delta \mathrm{h}_{\mathrm{t}}$ ), the percentage change in conditional variance from day $t-1$ to day $t$ ). $\mathrm{h}_{\mathrm{t}-1}$ is assumed to be equal the unconditional variance.

Figure 2(a) plots different impacts of equal positive and negative shocks on predicted volatility according to the estimates from the model (1-4) in the third collumn of Panel B in Table 2. Suppose that the conditional variance, $h_{t-1}=\operatorname{Var}\left(\zeta_{t-1}\right)$ is at its steady-state level. According to the estimates in the model, the conditional variance for day $t$ falls $8 \%$ if there was no price change on day $t-1$, increases $5.97 \%$ if the price fell $15 \%$, and increases $21.03 \%$ if the price increased $15 \%$. 


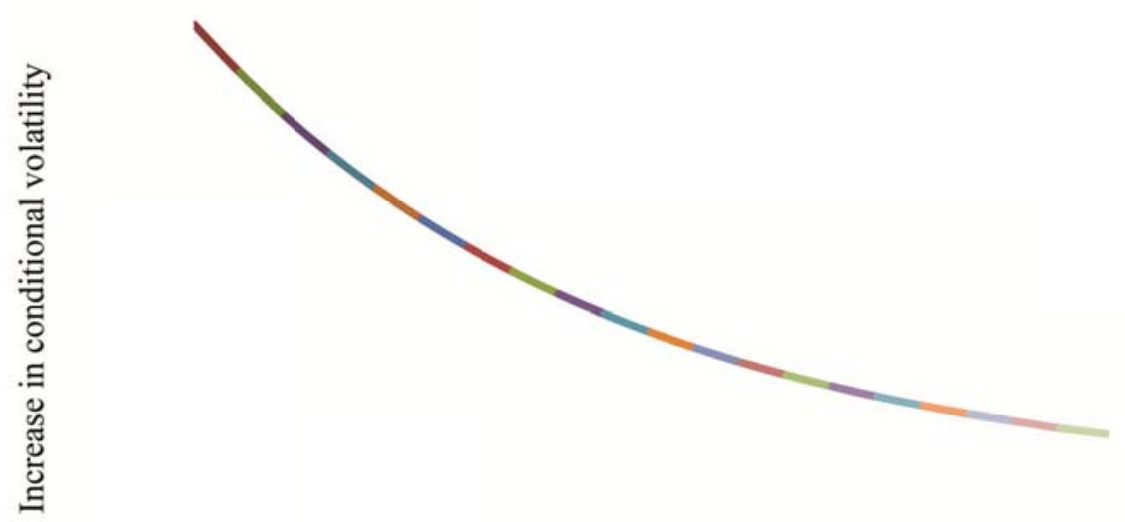

Trading day relative to shock

Figure 3. The change in conditional volatility following a return shock

This figure presents the impact of a two-standard deviation natural gas return shock on the predicted volatility. Suppose the conditional variance, $\mathrm{h}_{\mathrm{t}-1}=\operatorname{Var}\left(\zeta_{\mathrm{t}-1}\right)$ is at its steady-state level and suppose there is a shock such that $\zeta_{\mathrm{t}-1}^{2}=4 \operatorname{Var}\left(\zeta_{\mathrm{t}-1}\right)$. This figure demonstrates the percentage difference in expected volatility on day $t+x$ and on day $t-1,\left[\frac{\operatorname{Var}\left(\zeta_{\mathrm{t}+\mathrm{x}}\right)}{\operatorname{Var}\left(\zeta_{\mathrm{t}-1}\right)}-1\right]$, assuming $\mathrm{E}\left(\zeta_{\mathrm{t+ \textrm {x }}}^{2}\right)=\operatorname{Var}\left(\zeta_{t+x}\right)$ for $x>-1$ and that negative and positive return shocks are equally likely.

Figure 3 presents the impact of a two-standard deviation return shock on subsequent predicted volatilities in the natural gas market. Suppose the conditional variance, $h_{t-l}=$ Var $\left(\zeta_{\mathrm{t}-1}\right)$ is at its steady-state level and there is a shock such that $\zeta_{\mathrm{t}-1}^{2}=4 \operatorname{Var}\left(\zeta_{\mathrm{t}-1}\right)$. Figure 3 demonstrates the percentage difference in expected volatility on day $t+x$ and on day $t-1$, $\left[\frac{\operatorname{Var}\left(\zeta_{\mathrm{t}+\mathrm{x}}\right)}{\operatorname{Var}\left(\zeta_{\mathrm{t}-1}\right)}-1\right]$, assuming $\mathrm{E}\left(\zeta_{\mathrm{t}+\mathrm{x}}^{2}\right)=\operatorname{Var}\left(\zeta_{t+x}\right)$ for $x>-1$ and that negative and positive return shocks are equally likely. For example, the conditional volatility is about $14 \%$ higher the day after the shock and $7 \%$ a week later.

The second column of Panel B in Table 2 presents estimates of a GJR model as it would normally be estimated, i.e., without storage announcement, seasonality, bid week and weather effects. In other words, these are estimates from a model consisting of equations (1-3) only. A comparison of the estimates of the GJR model (in the second column) and those of the full model (in the third column) indicates that determinants of volatility other than volatility persistence and asymmetry are important when modeling volatility in the natural gas market. 
The likelihood ratio test statistics is 338.174 with 18 degrees of freedom and therefore, the null hypothesis of no announcement, seasonality, bid week or weather effects is rejected at the 0.001 level. In addition, the estimates of $\alpha$ and $(\alpha+\gamma)$ in the GJR model are significantly higher than those in the full model. Apparently, failing to control for announcement, seasonality, bid week and weather effects leads to an overestimation of the impact of a surprise return shock on subsequent volatility, and the estimate of the resulting percentage overestimation is $78.76 \%$. (Assuming negative and positive shocks are equally likely, the estimated average impact of day $t$ 's return shock on day $t+1$ 's volatility is $\alpha+.5 \gamma$. The overestimation is measured as: $\left(E_{w o} / E_{w}\right)-1$ where $E_{w o}$ represents the estimates of $\alpha+.5 \gamma$ in the second column of Table 2 where these effects are not controlled and $E_{w}$ those in the third column where they are).

Figure 2(b) plots different impacts of equal positive and negative shocks on predicted volatility according to the estimates from the GJR and the full models. Again, suppose the conditional variance, $h_{t-1}=\operatorname{Var}\left(\zeta_{\mathrm{t}-1}\right)$ is at its steady-state level. According to the estimates in the GJR model, the conditional variance for day $t$ increases $20.25 \%$ if the price fell $15 \%$, and increases $25.20 \%$ if the price increased $15 \%$ while according to the estimates in the full model, the increase in conditional variance for day $t$ are $5.97 \%$ and $21.03 \%$, respectively. To test whether the omission of announcement, seasonality, bid week or weather effects is responsible for this overestimation, an alternative model is estimated in which equation 4.b and just one of the equations $(4 \mathrm{a}, 4 \mathrm{c}, 4 \mathrm{~d}$ or $4 \mathrm{e})$ are dropped from the full model.

When equation 4(c) is dropped from the full model, the estimates of equation 3 are virtually unchanged from those in the second column and the overestimation of the impact of a surprise return shock on subsequent volatility is roughly $60 \%$. Therefore, failing to control for a month-of-the-year pattern in natural gas volatility is the main cause of the overestimation.

\subsection{Day-of-the-week and Storage Announcement}

The null hypothesis that $\lambda_{\text {Monday }}=\lambda_{\text {Wednesday }}=\lambda_{\text {Thursday }}=\lambda_{\text {Friday }}$ is rejected at the 0.01 level with the $\chi^{2}$ test statistics of 108.90 and 3 degrees of freedom, implying a significant day-of-the-week pattern in natural gas volatility. Since Tuesday is the left-out dummy, the coefficients in Panel B of Table 2 measure the difference between average volatility on each weekday and on Tuesday. Contrary to the findings for many financial markets (Note 11), there is no significant evidence of higher natural gas volatility on Friday. This may be explained by the fact that while Friday is the release day of important economic news in other markets, this is not the case for the natural gas market. Indeed, natural gas price volatility is likely to be lowest on Friday.

As expected, Monday return (including weekend) tends to be more volatile than any normal weekday return. During the 1997-2012 period, variance of the Friday-close-to-Monday-close return is $87.72 \%$ higher than variance of Tuesday return at the 0.001 level. Apparently, the natural gas market is impacted by sorts of news occurring during the weekend such as weather forecasts. 
Thursday has the second-highest coefficient estimate during the 1997-2012 period. Since the Natural Gas Storage Report was released on Wednesdays before May 06, 2002 (by the American Gas Association) and on Thursdays (by the EIA) since then, separate day-of-the-week volatility patterns are examined for the sub-periods before and after May 06, 2002. Results in the fourth column of Panel B in Table 2 indicate that from $01 / 1997$ to 5/2002, Thursday is associated with the second-highest coefficient estimate. The variance of Thursday return is $28.48 \%$ higher than that of Tuesday at the 0.05 level. Apparently, although Wednesday is the release day of the Storage Report in this period, there is no significant evidence of higher natural gas volatility on Wednesday than on other days of the week. This is possibly explained by the timing of the Report release. Prior to March 2, 2000, the AGA Storage Report was announced after the close of NYMEX trading on Wednesday and from March 2000 to May 2002 it was released at the interval of 2:00-2:15 pm on Wednesday during NYMEX trading hours. Consequently, news from the Storage Report apparently did not arrive in the market until the day following the announcement.

Results in the fifth column of Panel B in Table 2 indicate that during the 05/2002-12/2012 sub-period, the variance of Thursday return is $67.60 \%$ higher than that of Tuesday at the 0.01 level. Linn \& Zhu (2004) and Murry \& Zhu (2004) document that the high Thursday volatility is caused by the Natural Gas Storage Report announcement which is released on Thursday (except for holidays) since May 2002. However, if the Storage Report is the only cause of the increased volatility on Thursday, estimates from specification (1-4) should indicate no evidence of higher volatility on Thursday since the specification already controls for the impact of storage report on volatility (Andersen \& Bollerslev, 1998). Therefore, the evidence of an increase in natural gas volatility on Thursday even after the impact of storage report release has been controlled for implies that on Thursday, the market is impacted by news other than that from the storage report. Starting in May 2002, in addition to the Storage Report (which is released at 10:30 am), the EIA also releases the Natural Gas Weekly Update at 2:00 pm on Thursday. The Weekly Update summarizes weather conditions, spot and futures prices and other market trends over the preceding week. Apparently, certain news in the Weekly Update such as rig counts or transportation update is relevant to natural gas market participants.

As mentioned above, the level of working gas in storage often receives much attention in the natural gas market since it is widely considered as a measure of supply and demand balance in the market (Linn \& Zhu, 2004; Chiou-Wei et al., 2007). Consistent with the results in Chiou-Wei et al. (2007) of storage surprises impact on natural gas prices, results in the last column of Panel B in Table 2 indicate that storage surprise has a significantly positive impact on natural gas volatility. During the winter months (withdrawal season), news about a storage level which is lower (higher) than the market's expectation indicates a low (high) natural gas supply which causes upward (downward) pressure on market prices. During the refill season, news about a storage level which is lower (higher) than the market's expectation may increase (decrease) uncertainty regarding whether storage supplies will be sufficient to meet peak demand needs over the following winter. While not surprising given the findings in Linn \& Zhu (2004) and in Chiou-Wei et al. (2007), results in this research show a significant 
evidence of increased natural gas volatility in response to storage surprise even when the model has controlled for higher Thursday volatility often associated with storage announcement.

\subsection{Time-of-the-year Pattern and Weather Effect}

Consistent with the hypothesis of time-of-the-year impact on volatility, volatility in the natural gas market exhibits strong seasonality pattern which is illustrated in Figure 4 . The null hypothesis:

$\theta_{\text {Jan }}=\theta_{\text {Feb }}=\theta_{\text {March }}=\theta_{\text {April }}=\theta_{\text {May }}=\theta_{\text {July }}=\theta_{\text {August }}=\theta_{\text {Sept }}=\theta_{\text {October }}=\theta_{\text {November }}=\theta_{\text {December }}$ is rejected at the 0.01 level with the $\chi^{2}$ test statistics of 23.93 and 10 degrees of freedom, implying that natural gas volatility significantly differs by month of the year.

Table 4. Time-of-the-year pattern

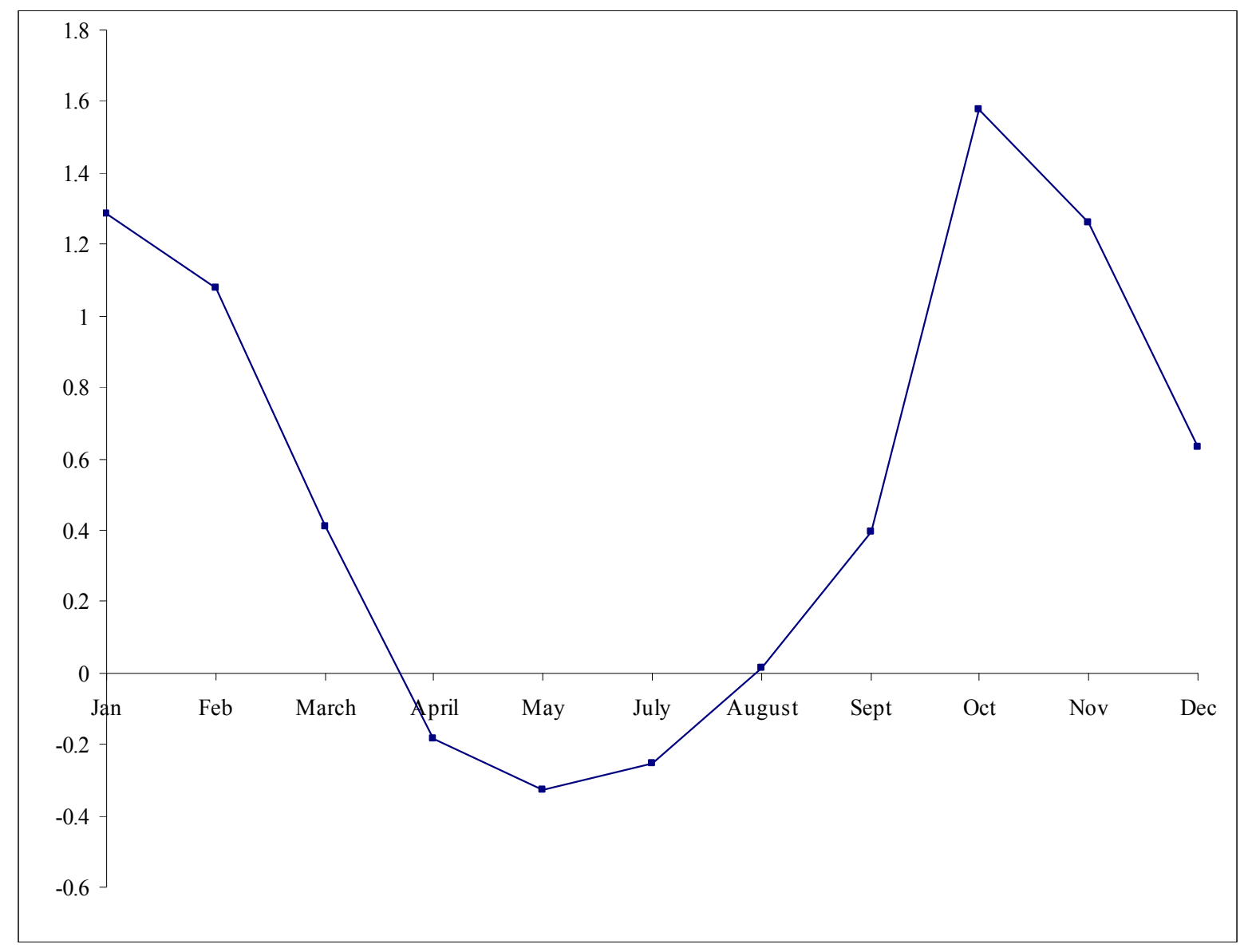

This figure presents the month-of-the-year pattern according to the estimates in the third column of Panel B in Table 2. The vertical axis depicts the ratio of the average variance of natural gas volatility on the futures contract expiring in a certain month to that on the futures contract expiring in June. 
Volatility tends to be highest from October through February. As heating needs dominate the market from December through February (Fleming, Kirby, \& Ostdiek, 2006), demand for natural gas may rise sharply during these months and at the same time, natural gas supply is essentially fixed due to storage constraint. Consequently, the inelasticity of natural gas supply and demand can cause large price swings in order to balance supply and demand in cold winter. November is the first month of the heating season (Note 12) and therefore decisions made during this month tend to impact the volumes in storage for the rest of the upcoming heating season. As natural gas suppliers are uncertain about the levels of supply and demand for the months later in the winter whose overall severity is unknown this early in the withdrawal season, fluctuations in demands are not necessarily met readily with working gas in storage (EIA's Publication, 2007). Consequently, price spikes may occur during this month.

Surprisingly natural gas prices tend to be most volatile in October. During October, the last month of the injection season, storage facility owners may be competing heavily to inject natural gas for the winter season. This increased competition from storage facilities looking to meet injection refill goals is often coupled with uncertainty regarding whether or not there will be sufficient supplies to meet heating needs in the upcoming heating season (EIA's Publication, 2007).

The milder spring and summer months exhibit lowest average levels of natural gas volatility. During March and April, the peak winter demand is generally complete and thus, there is less uncertainty regarding supply and demand imbalance (EIA's Publication, 2007). Although winter-like temperatures sometimes persist into April, it is during this month that natural gas activities tend to switch from storage withdrawals towards storage injection (Note 13).

Overall, there is a strong month-of-the-year pattern in natural gas volatility. During the winter months, both supply and demand are relatively inelastic and therefore, natural gas prices tend to swing more in order to balance supply and demand. Given that either natural gas supplies may not keep pace with the increased demand or a prediction of high demand may not materialize because of mild weather during winter season, months with higher levels of market tightness and/or market uncertainty often exhibit greater volatility.

The coefficient estimate of $\kappa$ is positive and significant at the 0.01 level implying an increase in natural gas volatility on winter days when the average temperature in the main consumption regions falls below the 30 -year average. This result is robust after the month-of-the-year pattern is controlled for.

\subsection{Bid Week Effect}

There is strong evidence of an increase in natural gas volatility during bid week. In the sample period, the estimated increase in average volatility in the last five trading days each month is $65.92 \%$, which is significant at the 0.01 level. As hypothesized above, the increased volatility during bid week is attributable to two reasons. First, as marketers' bids for natural gas to be delivered in the upcoming months are revealed and spot contracts are signed, this sort of news contains information which moves prices in the futures market. Second, the first three trading days of the bid week could be associated with higher volatility in the futures 
market since the nearby futures contract is expiring and traders are having to reverse their positions.

There is also significant evidence of an increase in natural gas volatility on the day following bid week (the first trading day of a month). As mentioned above, bid week news differs from scheduled announcements in that while the latter is available to all market participants at the same expected time, prices and volumes being set during bid week leak from contract signings and therefore, part of this information may not become public knowledge until the following day. Therefore, volatility could continue increasing on the day following bid week as prices and volumes being set in the spot markets become public information. Results from an expanded specification with dummy variables for both the first and the second trading days of a month (Note 14) show no significant evidence that volatility continues to increase on the second day. Apparently, as bid week news arrives in the futures market, market participants complete price adjustments by the end of the first trading day of a month.

\section{Robustness Check}

The results documented in sections 5 are obtained from the estimation of a GARCH-type specification in which return is measured by log percentage change in price. To test the validity of these results, this study uses extreme value estimator, a different measure of volatility developed by Parkinson (1980). Extreme value estimator is widely used in numerous studies, including Wiggins (1992), Martens \& Van Dijk (2007) and Cao, Chang, \& Wang (2008). The extreme value estimator of volatility on day $t$ is calculated as:

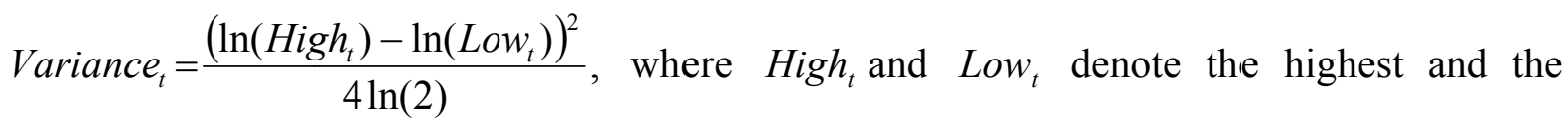

lowest prices on day $t$, respectively.

Table 3. Robustness check

\begin{tabular}{|l|l|l|l|l|l|l|}
\hline & \multicolumn{2}{|l}{$1997-2012$} & \multicolumn{2}{l|}{$1997-2002$} & $2002-2012$ \\
\hline & Estimate & Std. error & Estimate & Std. error & Estimate & Std. error \\
\hline$\omega^{\prime}\left(\mathrm{x} 10^{2}\right)$ & $0.2922^{*}$ & 0.1331 & $-0.0442^{* *}$ & 0.2326 & $0.4472^{*}$ & 0.1803 \\
\hline Std $(-1)$ & $0.1828^{* *}$ & 0.0546 & $0.1929^{* *}$ & 0.0637 & $0.1083^{* *}$ & 0.0417 \\
\hline Std $(-2)$ & $0.1379^{* *}$ & 0.0324 & $0.0937^{*}$ & 0.0411 & $0.1724^{* *}$ & 0.0325 \\
\hline Std $(-3)$ & $0.0604^{*}$ & 0.0291 & $0.0732^{*}$ & 0.0349 & $0.0588^{*}$ & 0.0329 \\
\hline Std $(-4)$ & $0.1119^{* *}$ & 0.0265 & $0.0929^{*}$ & 0.0387 & $0.1148^{* *}$ & 0.0323 \\
\hline Std $(-5)$ & $0.0805^{* *}$ & 0.0299 & $0.0830^{*}$ & 0.0345 & $0.0599^{*}$ & 0.0319 \\
\hline$\varepsilon_{t}^{\{+\}}$ & $0.0862^{*}$ & 0.0428 & 0.0913 & 0.0715 & $0.0874^{* *}$ & 0.0223 \\
\hline$\varepsilon_{t}^{\{-\}}$ & -0.0009 & 0.0222 & 0.0084 & 0.0371 & -0.0261 & 0.0247 \\
\hline Monday $\left(\mathrm{x} 10^{2}\right)$ & $0.3482^{* *}$ & 0.1172 & $0.4871^{* *}$ & 0.1768 & $0.2512^{*}$ & 0.1161 \\
\hline $\begin{array}{l}\text { Wednesday } \\
\left(\mathrm{x} 10^{2}\right)\end{array}$ & $0.1761^{*}$ & 0.0877 & 0.1845 & 0.1195 & $0.1945^{*}$ & 0.1122 \\
\hline Thursday $\left(\mathrm{x} 10^{2}\right)$ & $0.5971^{* *}$ & 0.0924 & $0.7274^{* *}$ & 0.1298 & $0.2243^{*}$ & 0.1335 \\
\hline Friday $\left(\mathrm{x} 10^{2}\right)$ & $-0.2200^{*}$ & 0.0863 & $-0.2812^{*}$ & 0.1136 & -0.1311 & 0.1134 \\
\hline W $\left(\mathrm{x} 10^{2}\right)$ & $0.1227^{*}$ & 0.0721 & 0.1512 & 0.1133 & 0.1057 & 0.0923 \\
\hline January $\left(\mathrm{x} 10^{2}\right)$ & $0.2617^{*}$ & 0.1375 & $0.5075^{*}$ & 0.2221 & $0.3099^{*}$ & 0.1738 \\
\hline February $\left(\mathrm{x} 10^{2}\right)$ & $0.4132^{* *}$ & 0.1322 & $0.5651^{* *}$ & 0.2062 & 0.1803 & 0.1875 \\
\hline
\end{tabular}




\begin{tabular}{|l|l|l|l|l|l|l|}
\hline March $\left(\mathrm{x} 10^{2}\right)$ & $0.4182^{*}$ & 0.2471 & 0.6282 & 0.4563 & $0.3499^{*}$ & 0.1885 \\
\hline April $\left(\mathrm{x} 10^{2}\right)$ & -0.0693 & 0.0929 & -0.0672 & 0.1382 & 0.0287 & 0.1786 \\
\hline May $\left(\mathrm{x} 10^{2}\right)$ & 0.0918 & 0.0866 & -0.0253 & 0.1166 & 0.0654 & 0.1696 \\
\hline July $\left(\times 10^{2}\right)$ & 0.1477 & 0.0954 & $0.2673^{*}$ & 0.1288 & 0.1178 & 0.1719 \\
\hline August $\left(\mathrm{x} 10^{2}\right)$ & $0.2414^{*}$ & 0.1132 & 0.1937 & 0.1496 & $0.3945^{*}$ & 0.1767 \\
\hline September $\left(\mathrm{x} 10^{2}\right)$ & $0.4985^{* *}$ & 0.1201 & $0.3825^{* *}$ & 0.1312 & $0.8041^{* *}$ & 0.1797 \\
\hline October $\left(\mathrm{x} 10^{2}\right)$ & $0.6022^{* *}$ & 0.1352 & $0.5978^{* *}$ & 0.1667 & $0.8272^{* *}$ & 0.1947 \\
\hline November $\left(\mathrm{x} 10^{2}\right)$ & $0.2732^{*}$ & 0.1261 & $0.4056^{* *}$ & 0.1571 & 0.2815 & 0.1738 \\
\hline December $\left(\times 10^{2}\right)$ & $0.3724^{* *}$ & 0.1219 & $0.6243^{* *}$ & 0.1862 & $0.3424^{*}$ & 0.1766 \\
\hline BW $\left(\mathrm{x} 10^{2}\right)$ & $0.1658^{*}$ & 0.0736 & $0.2661^{*}$ & 0.1116 & 0.1177 & 0.0848 \\
\hline ABW $\left(\mathrm{x} 10^{2}\right)$ & 0.2039 & 0.1363 & 0.0482 & 0.1669 & 0.2653 & 0.1739 \\
\hline OilStd & $0.1431^{* *}$ & 0.0337 & $0.2943^{* *}$ & 0.0591 & $0.1265^{* *}$ & 0.0298 \\
\hline SR ${ }_{t}\left(\mathrm{x} 10^{2}\right)$ & & & & & $0.4746^{* *}$ & 0.1542 \\
\hline Adjusted R & 0.3221 & & 0.3334 & & 0.3562 & \\
\hline
\end{tabular}

Table 3 presents the estimates of the following model:

$$
\begin{aligned}
& S t d_{t}=\omega^{\prime}+\sum_{i=1}^{5} \alpha_{i} S t d_{t-i}+\gamma_{1} \varepsilon_{t-1}^{\{+\}}+\gamma_{2} \varepsilon_{t-1}^{\{-\}}+\sum_{j=1}^{4} \lambda_{j}^{\prime} D W_{j, t}+\kappa^{\prime} S R_{t}+\sum_{k=1}^{11} \theta_{k}^{\prime} D M_{k, t} \\
& +\psi^{\prime} W_{t}+\delta_{0}^{\prime} B W_{t}+\delta_{1}^{\prime} A B W_{t}+\rho O i l S t d_{t}+e_{t}
\end{aligned}
$$

$S t d_{t}=\frac{\mid \ln \left(H i g h_{t}\right)-\ln \left(\text { Low }_{t}\right) \mid}{2 \sqrt{\ln (2)}}, H_{i g h}$ and Low denote the highest and the lowest prices of the

nearby natural gas futures contract on day $t$, respectively. $r_{t}=\ln \left(P_{t} / P_{t-1}\right)$ where $P_{t}$ is the price of the nearby futures contract on day $t$ and $P_{t-1}$ is the price of the same contract the previous day. $\varepsilon_{t-1}^{\{+\}}=\varepsilon_{t-1}$ if $\varepsilon_{t-1} \geq 0$ and 0 otherwise; $\varepsilon_{t-1}^{\{-\}}=\varepsilon_{t-1}$ if $\varepsilon_{t-1}<0$ and 0 otherwise and $\varepsilon_{t}$ is the residual from the mean equation, equation (1):

$r_{t}=\mu+a_{1}$ Oilret $_{t}+a_{2}$ CddDif $_{t}+a_{3}$HddDif $_{t}^{\{+\}}+a_{4}$ HddDift $_{t}^{\{-\}}+a_{5} \operatorname{SRFE}_{t}+\sum_{i=1}^{4} \vartheta_{i} D W_{i, t}+\varepsilon_{t}$

$D W_{j, t}$ are zero-one dummies for Monday, Wednesday, Thursday and Friday. $S R_{t}=\frac{\left|S R F E_{t}\right|}{S_{S R}}$ on days the storage report announcement is released and 0 otherwise where $S R F E_{t}$ is the surprise in the change in storage $=$ the actual storage change (reported in the EIA report) - the consensus expected storage change (reported by Bloomberg prior to the EIA report release) and $s_{S R}$ is the sample standard deviation of $\left|S R F E_{t}\right| . D M_{k, t}=1$ if the futures contract observed on day t expires in month $k . W_{t}=1$ if the difference between the actual Heating Degree Day measure and the 30-year normal HDD measure for day $\mathrm{t}\left(H d d D i f_{t}\right)$ is $<0$ and $\mathrm{W}_{\mathrm{t}}=0$ otherwise. $B W_{t}$ is 1 if day $t$ is one of the last five trading days in a month and 0 otherwise. $A B W_{t}=1$ if day $t$ is the first trading day in a month. OilStd $_{t}=\frac{\mid \ln \left(\text { OilHigh }_{t}\right)-\ln \left(\text { OilLow }_{t}\right) \mid}{2 \sqrt{\ln (2)}}$, OilHigh $_{t}$ and 
OilLow $_{t}$ denote the highest and the lowest prices of the nearby crude oil futures contract on day $t$, respectively. $\left(^{* *}\right)$ and $\left(^{*}\right)$ designate estimates significantly different from zero at the 0.01 and 0.05 levels, respectively. The sample extends from January 02, 1997 to December 31, 2012.

The following specification is developed from the hypotheses in Section 2:

$$
\begin{aligned}
& S t d_{t}=\omega^{\prime}+\sum_{i=1}^{5} \alpha_{i} S t d_{t-i}+\gamma_{1} \varepsilon_{t-1}^{\{+\}}+\gamma_{2} \varepsilon_{t-1}^{\{-\}}+\sum_{j=1}^{4} \lambda_{j}^{\prime} D W_{j, t}+\kappa^{\prime} S R_{t}+\sum_{k=1}^{11} \theta_{k}^{\prime} D M_{k, t} \\
& +\psi^{\prime} W_{t}+\delta_{0}^{\prime} B W_{t}+\delta_{1}^{\prime} A B W_{t}+\rho O i l S t d_{t}+e_{t}
\end{aligned}
$$

$S t d_{t}=\frac{\left|\ln \left(H i g h_{t}\right)-\ln \left(L o w_{t}\right)\right|}{2 \sqrt{\ln (2)}}, H i g h_{t}$ and Low ${ }_{t}$ denote the highest and the lowest prices of the nearby natural gas futures contract on day $t$, respectively. $r_{t}=\ln \left(P_{t} / P_{t-1}\right)$ where $P_{t}$ is the price of the nearby futures contract on day $t$ and $P_{t-1}$ is the price of the same contract the previous day. $\varepsilon_{t-1}^{\{+\}}=\varepsilon_{t-1}$ if $\varepsilon_{t-1}>0$ and 0 otherwise; $\varepsilon_{t-1}^{\{-\}}=\varepsilon_{t-1}$ if $\varepsilon_{t-1}<0$ and 0 otherwise and $\varepsilon_{t}$ is the residual from the mean equation, equation (1):

$$
r_{t}=\mu+a_{1} \text { Oilret }_{t}+a_{2} \text { CddDif }_{t}+a_{3} \text { HddDif }_{t}^{\{+\}}+a_{4} \text { HddDif }_{t}^{\{-\}}+a_{5} S R F E_{t}+\sum_{i=1}^{4} \vartheta_{i} D W_{i, t}+\varepsilon_{t}
$$

$D W_{j, t}$ are zero-one dummies for Monday, Wednesday, Thursday and Friday with Tuesday being the left-out day. $S R_{t}=\frac{\left|S R F E_{t}\right|}{S_{S R}}$ on days the storage report announcement is released and 0 otherwise. $S R F E_{t}$ is the surprise in the storage change = the actual storage change (reported in the EIA report) - the consensus expected storage change (reported by Bloomberg prior to the EIA report release) and $s_{S R}$ is the sample standard deviation of $\left|S R F E_{t}\right|$. $D M_{k, t}=1$ if the futures contract observed on day $\mathrm{t}$ expires in month $k . W_{t}=1$ if the difference between the actual Heating Degree Day measure and the 30-year normal HDD measure for day $\mathrm{t}\left(\right.$ HddDif $\left._{t}\right)$ is $<0$ and $\mathrm{W}_{\mathrm{t}}=0$ otherwise. $B W_{t}=1$ if day $t$ is one of the last five trading days in a month and 0 otherwise. $A B W_{t}=1$ if day $t$ is the first trading day in a month.

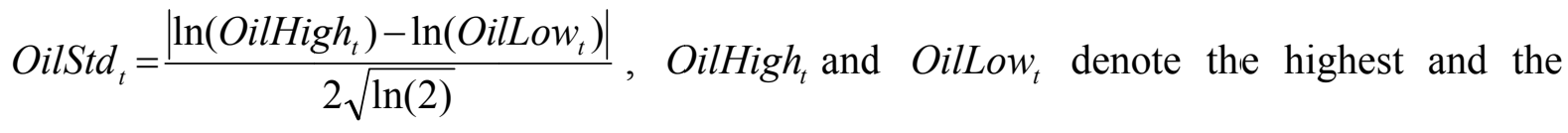
lowest prices of the nearby crude oil futures contract on day $t$, respectively.

Equation (7) is estimated by OLS with Newey \& West (1987) correction for both heteroskedasticity and autocorrelation. Results are presented in Table 3. Consistent with the results in Section 5.2, there is significant evidence of volatility persistence when volatility is estimated by the extreme-value method. The coefficients of the five lagged Std are positive 
and significant at the 0.05 level, indicating high volatility days tend to be followed by high volatility days and low volatility days tend to be followed by low volatility days. There is evidence that a positive return shock leads to higher Std at the 0.05 level but there is no significant evidence that a negative shock leads to higher $S t d$, indicating natural gas volatility is more responsive to previous positive shocks than to negative shocks.

The null hypotheses: $\lambda_{\text {Monday }}^{\prime}=\lambda_{\text {Wednesday }}^{\prime}=\lambda_{\text {Thursday }}^{\prime}=\lambda_{\text {Friday }}^{\prime}=0$ and $\theta_{\text {Jan }}^{\prime}=\theta_{\text {Feb }}^{\prime}=\theta_{\text {March }}^{\prime}=\theta_{\text {April }}^{\prime}=$ $\theta_{\text {May }}^{\prime}=\theta_{\text {July }}^{\prime}=\theta_{\text {August }}^{\prime}=\theta_{\text {Sept }}^{\prime}=\theta_{\text {Oct }}^{\prime}=\theta_{\text {Nov }}^{\prime}=\theta_{\text {Dec }}^{\prime}=0$ are both rejected at the 0.01 level, indicating day-of-the-week and time-of-the-year patterns in natural gas volatility as documented in Section 5. There is no significant evidence that natural gas volatility, when volatility is measured by the extreme value method, is highest on Monday. Apparently, the high Monday/weekend volatility as documented in Section 5.3 is mainly attributable to the accumulation of information over the weekend. Thursday tends to be the most volatile day of the week. Again, this evidence is consistent with the fact that after May 2002, the Storage Report is released on Thursday and before April 2000, this was the day news about storage report actually arrived in the market. There is significant evidence, at the 0.05 level, that natural gas volatility, as measured by the extreme value method, is higher on winter days with lower than normal temperature. Natural gas volatility also tends to increase on days during the bid week. However, there is no significant evidence of an increase in volatility on days immediately following the bid week. Consistent with the findings in Section 5, natural gas volatility tends to be high for futures contracts expiring in the months from September to March. There is significant evidence of a spillover effect in which crude oil volatility has a positive impact on natural gas volatility. This evidence is consistent with the findings that crude oil price is a significant predictor of natural gas price.

The last two columns in Table 3 present the estimation results for the May 2002- December 2012 sub-period. These results are similar to those for the entire sample period. The coefficient estimate of $\kappa^{\prime}$ is positive and significant at the 0.01 level, which is consistent with the evidence that surprises in the natural gas in storage change has a positive impact on price volatility.

\section{Summary and Conclusions}

The contribution this paper makes is to provide an empirical examination of the causes and behavior of price volatility in the natural gas market. Daily returns data from January 1997 through December 2012 are used to estimate a multiplicative GARCH type model. This model, which separates volatility into a persistent part and a non-persistent part, allows us to implement a much cleaner study of the determinants of volatility than that used in some previous studies.

The natural gas market is characterized by volatility, implying highly volatile periods are followed by highly volatile periods and stable periods are followed by stable ones. A positive shock in natural gas prices tends to have higher impact on predicted volatility than an equivalent negative shock. There is a day-of-the-week pattern in natural gas volatility. 
Monday return (including weekend) is more volatile than any other weekdlay return. The high weekend/Monday volatility is mainly due to the accumulation of information over the weekend. In contrast to the findings for some financial markets, natural gas price volatility tends to be lowest on Friday. There is evidence of an increase in volatility on Thursday which is attributable to the announcement of the Weekly Natural Gas Storage Report and the Natural Gas Update. The "surprise" news about the level of natural gas in storage has a significantly positive impact on natural gas volatility.

There is a strong time-of-the-year pattern in that volatility tends to be highest from October through February, which is likely caused by the inelasticity of natural gas supply and demand during winter. Volatility also tends to be higher on winter days when the temperature is lower than normal. There is evidence of an increase in natural gas price volatility during bid week as news about prices and volumes being set in the spot market leaks to the futures market. Volatility continues to be higher on the day immediately following bid week, the day when all bid week news becomes public.

To check the robustness of the above findings, this study estimates a different specification wherein volatility is measured by the extreme-value method. Results from the robustness check indicate that (1) natural gas volatility is significantly determined by volatility level on previous days, (2) a positive return shock has a significantly positive impact on volatility, (3) there are day-of-the-week and time-of-the-year patterns in volatility, (4) "surprise" news about changes of natural gas in storage has a significantly positive impact on volatility, (5) volatility tends to increase during bid week and (6) crude oil volatility has a significantly positive impact on natural gas volatility.

\section{Acknowledgement}

I am grateful to Louis Ederington for helpful comments and suggestions. I benefit from the suggestions of Duane Stock, Chitru Fernando, Scott Linn, Xin Huang, and Marian Turac. I appreciate comments from participants in Marietta College's Faculty Publishing Group. All mistakes remain my responsibility.

\section{References}

Andersen, T. G., \& Bollerslev, T. (1998). Deutschemark-Dollar Volatility: Intraday Activity Patterns, Macroeconomic Announcements, and Longer Run Dependencies. Journal of Finance, 53, 219-265. https://doi.org/10.1111/0022-1082.85732

Andersen, T. G., Bollerslev, T., Diebold, F. X., \& Vega, C. (2003). Micro Effects of Macro Announcements: Real-Time Price Discovery in Foreign Exchange. American Economic Review, 93, 38-62. https://doi.org/10.1257/000282803321455151

Balduzzi, P., Elton, E. J., \& Green, T. C. (2001). Economic News and Bond Prices: Evidence from the U.S. Treasury Market. Journal of Financial and Quantitative Analysis, 36, 523-544. https://doi.org/10.2307/2676223

Berument, H., \& Kiymaz, H. (2001). The Day of the Week Effect on Stock Market Volatility. Journal of Economics and Finance, 25, 181-193. https://doi.org/10.1007/BF02744521 
Burns, J. H. (2008). The Commodity Futures Trading Commission, Nova Science Publishers.

Cao, C., Chang, E. C., \& Wang, Y. (2008). An Empirical Analysis of the Dynamic Relationship between Mutual Fund Flow and Market Return Volatility. Journal of Banking and Finance, 32, 2111-2123. https://doi.org/10.1016/j.jbankfin.2007.12.035

Chiou-Wei, S. Z., Linn, C., \& Zhu, Z. (2007). Fundamental News and the Behavior of Commodity Prices: Price Discovery and Jumps in U.S. Natural Gas Futures and Spot Prices. Working Paper.

De Goeij, P., \& Marquering, W. (2006). Macroeconomic Announcements and Asymmetric Volatility in Bond Returns. Journal of Banking and Finance, 30, 2659-2680. https://doi.org/10.1016/j.jbankfin.2005.09.014

Ederington, L. H., \& Lee, J. H. (1993). How Markets Process Information: New Releases and Volatility. Journal of Finance, 48, 1161-1191. https://doi.org/10.1111/j.1540-6261.1993.tb04750.x

Ederington, L. H., \& Lee, J. H. (1995). The Short-run Dynamics of the Price Adjustment to New Information. Journal of Financial and Quantitative Analysis, 30, 117-134. https://doi.org/10.2307/2331256

Ederington, L. H., \& Lee, J. H. (2001). Volatility in Interest-rate and Foreign-exchange Markets: ARCH, Announcement, and Seasonality Effects. Journal of Futures Markets, 21, 17-552. https://doi.org/10.1002/fut.1602

Flannery, M. J., \& Protopapadakis, A. A. (2002). Macroeconomic Factors Do Influence Aggregate Stock Returns. Review of Financial Studies, 15, 751-782. https://doi.org/10.1093/rfs/15.3.751

Fleming, J., Kirby, C., \& Ostdiek, B. (2006). Information, Trading and Volatility: Evidence from Weather-Sensitive Markets. Journal of Finance, 61, 2899-2930. https://doi.org/10.1111/j.1540-6261.2006.01007.x

Gay, G. D., Simkins, B. J., \& Turac, M. (2007). Analyst Forecasts and Price Discovery in Futures Markets: The Case of Natural Gas Storage. Working Paper.

Glosten, L. R., Jagannathan, R., \& Runkle, D. E. (1993). On the Relation between the Expected Value and the Volatility of the Nominal Excess Return on Stocks. Journal of Finance, 48, 1779-1801. https://doi.org/10.1111/j.1540-6261.1993.tb05128.x

Harvey, C. R., \& Huang, R. D. (1991). Volatility in the Foreign-currency Futures Market. Review of Financial Studies, 4, 543-569. https://doi.org/10.1093/rfs/4.3.543

Hsieh, D. A. (1989). Modeling Heteroskedasticity in Daily Foreign Exchange Rates. Journal of Business and Economic Statistics, 7, 307-317.

Jones, C. M., Lamont, O., \& Lumsdaine, R. L. (1998). Macroeconomic News and Bond Market Volatility. Journal of Financial Economics, 47, 315-337. https://doi.org/10.1016/S0304-405X(97)00047-0 
Krichene, N. (2002). World Crude Oil and Natural Gas: A Demand and Supply Model. Energy Economics, 24, 557-576. https://doi.org/10.1016/S0140-9883(02)00061-0

Lee, J. (2002). Federal Funds Rate Target Changes and Interest Rate Volatility. Journal of Economics and Business, 54, 159-191. https://doi.org/10.1016/S0148-6195(01)00061-3

Linn, S. C., \& Zhu, Z. (2004). Natural Gas Prices and the Gas Storage Report: Public News and Volatility in Energy Futures Markets. Journal of Futures Markets, 24, 283-313. https://doi.org/10.1002/fut.10115

Martens, M., \& Van Dijk, D. (2007). Measuring Volatility with the Realized Range. Journal of Econometrics, 138, 181-207. https://doi.org/10.1016/j.jeconom.2006.05.019

$\mathrm{Mu}$, X. (2007). Weather, Storage, and Natural Gas Price dynamics: Fundamentals and Volatility. Energy Economics, 29, 46-63. https://doi.org/10.1016/j.eneco.2006.04.003

Murry, D., \& Zhu, Z. (2004). EnronOnline and Informational Efficiency in the U.S. Natural Gas Market. Energy Journal, $25, \quad$ 57-74. https://doi.org/10.5547/ISSN0195-6574-EJ-Vol25-No2-3

Parkinson, M. (1980). Extreme Value Method for Estimating the Variance of the Rate of Return. Journal of Business, 53, 61-65. https://doi.org/10.1086/296071

Pindyck, R. (2004). Volatility in Natural Gas and Oil Markets. Journal of Energy and Development, 30, 1-19.

Susmel, R., \& Thompson, A. (1997). Volatility, Storage and Convenience: Evidence from Natural Gas Markets. Journal of Futures Markets, 17, 17-43. https://doi.org/10.1002/(SICI)1096-9934(199702)17:1<17::AID-FUT2>3.0.CO;2-J

Wiggins, J. B. (1991). Empirical Tests of the Bias and Efficiency of the Extreme-Value Variance Estimator for Common Stocks. Journal of Business, 64, 417-432. https://doi.org/10.1086/296544

Wiggins, J. B. (1992). Estimating the Volatility of S\&P 500 Futures Prices using the Extreme-Value Method. Journal of Futures Markets, 12, 265-273. https://doi.org/10.1002/fut.3990120303

\section{Notes}

Note 1. http://investor.cmegroup.com/investor-relations/releasedetail.cfm?ReleaseID=823160

Note 2. The data for the S\&P 500, US dollar-Euro exchange rate, and the 10-year T-bond interest rates were collected from CRSP database and the Federall Reserve website (http://www.federalreserve.gov).

Note 3. U.S. Natural Gas Markets: Mid-Term Prospects for Natural Gas Supply, EIA, 2001.

Note 4. Issue Brief 2001-03, Policy Analysis Group, American Gas Association. 


\section{Macrothink}

Note 5. Suenaga, Smith, \& Williams (2008) is the only research to date which documents a seasonality pattern in natural gas volatility.

Note 6. Understanding Natural Gas Markets, API, 2006.

Note 7. http://www.eia.gov/dnav/ng/hist/rngc1d.htm

Note 8 . The daily natural gas "returns" are used to measure price changes only. These "returns" are not investment returns since no money is actually invested.

Note 9. Wiggins $(1991,1992)$ document that the efficiency of the extreme value estimator significantly exceeds that of the close-to-close estimator of volatility.

Note 10. The Bloomberg survey procedure is summarized in Gay, Simkins, \& Turac (2007) as follows. By Tuesday of each week, a Bloomberg employee calls each analyst or receives an email containing the analyst's forecast. Many analysts provide a range for their estimated change in storage. In these cases, Bloomberg uses the midpoint of the range. Bloomberg then computes a "consensus estimate" based on the arithmetic average of the analyst forecasts. The first Bloomberg estimate of each week is typically prepared and released on Tuesday morning when at least one half of the analysts have reported. Updates are released if additional forecasts are received.

Note 11. For example, Harvey \& Huang (1991) reported higher volatility in interest rate and foreign exchange futures market on Friday. Ederington \& Lee (1993) further supported these results. Jones et al. (1998) and Berument \& Kiymaz (2001) found similar evidence for the bond and stock markets.

Note 12. Using data reported in the EIA's Natural Gas Weekly Storage Report (various issues), I determine that natural gas withdrawals normally begin in November and end in March.

Note 13. Based on data reported in the EIA's Natural Gas Weekly Storage Report (various issues), it is calculated that natural gas injections normally begin in April.

Note 14. Results will be provided upon request.

\section{Copyright Disclaimer}

Copyright for this article is retained by the author(s), with first publication rights granted to the journal.

This is an open-access article distributed under the terms and conditions of the Creative Commons Attribution license (http://creativecommons.org/licenses/by/3.0/). 